\title{
Volatility Bounds, Size, and Real Activity Prediction
}

\author{
Belén Nieto \\ University of Alicante, Spain \\ Gonzalo Rubio* \\ University CEU Cardenal Herrera, Spain
}

This version: October 16, 2012

\begin{abstract}
This paper shows how to extract future real activity information from optimallycombined size-sorted portfolios. In particular, we analyze the capacity of the size-based model-free Hansen-Jagannathan volatility bound to predict future economic growth. We find that the volatility bound is a powerful in-sample and out-of-sample predictor of future industrial production growth. The asymmetric sensitivities of small and large companies through the business cycle are behind our findings. Alternative volatility bounds estimated with sorting procedures based on book-to-market, momentum, or dividend yield do not either show these asymmetric sensitivities or forecasting capacity of output growth.
\end{abstract}

\section{JEL classification: G10; G12; E44}

Keywords: Financial uncertainty; volatility bounds; real activity; sorting stocks; predictability; size

An earlier version of this paper was circulated under the title Volatility Bounds, Sorting Stocks, and Real Activity Prediction. It was presented at the Luxembourg School of Finance, Universidad de Navarra, the workshop on Financial System Perspectives After the Crisis at the Universidad de Girona, the 2nd International Conference on Securities Markets at the Spanish Securities Exchange Commission, and the XX Foro de Finanzas at the Universidad de Oviedo. We thank seminar participants and Joss van Bommel, Tibor Neugebauer, Sara Ferreira-Filipe, Antonio Moreno, Germán López, Carmen Aranda, Burton Hollifiled, Ricardo Laborda, Antonio Rubia, and an anonymous referee for helpful comments and suggestions that substantially improved the contents of the paper. The authors acknowledge financial support from Ministerio de Educación y Ciencia and Ministerio de Economía y Competitividad through grants ECO2011-29751 (Belén Nieto, belen.nieto@ua.es) and ECO2012-34268 (Gonzalo Rubio, gonzalo.rubio@uch.ceu.es) respectively. Gonzalo Rubio also acknowledges financial support from Generalitat Valenciana grant PROMETEO 2008/106, and Copernicus4/2011. We assume full responsibility for any remaining errors.

* Corresponding author. E-mail address gonzalo.rubio@uch.ceu.es. 


\section{Introduction}

Does financial uncertainty predict future real activity? The answer to this question is particularly relevant after the recent turmoil experienced by industrial economies over the world. This paper shows that changes in the uncertainty embedded in stock prices are a powerful indicator of future economic growth. ${ }^{1}$ However, it is also the case that the information contained in the market capitalization of trading assets is a key issue for optimally detecting the impact of financial uncertainty in future real activity.

Size has always been a key research topic in both Economics and Finance. Firm size is present when analyzing apparently different topics like seasonality of stock returns, economies of scale, market power, synergy externalities, collaterals, and so on. In this paper we report additional evidence regarding the importance of size. Our main contribution is to show how to optimally extract the information contained in sizesorted portfolios to generate powerful in-sample and out-of-sample predictions of real activity. Our forecasting results are therefore a consequence of combining both the relevance of size, and the particular estimator we propose to predict future economic growth.

It has been recognized for a long time that the stock market is a leading economic indicator. The original papers by Fama $(1981,1990)$, and Schwert (1990) argue that stock returns at monthly, quarterly and annual frequencies are highly correlated with future output growth rates and this predicting ability increases with the length of the horizon. Similarly, Stock and Watson (2003) provide a comprehensive analysis of the forecasting capacity of different variables related to financial markets in forecasting production and inflation. They find that short and long interest rates, the term spread

\footnotetext{
${ }^{1}$ Bloom (2009) argues that uncertainty shocks, approximated by stock market volatility, cause firms with non-convex labor and capital adjustment costs to delay hiring and investment since higher uncertainty increases the real option value of waiting. Aggregate growth productivity then falls after the uncertainty shock because the adverse effects in employment and investment slow down the reallocation from low- to high-productivity firms, which explains the real activity growth rate in the economy.
} 
and the stock market index improve the forecast of real gross domestic product (GDP) growth, although they also point out non-trivial instability problems inherent in the predictive relations.

Additionally, direct measures of uncertainty from financial markets seem to have relevant information about macroeconomic variables in the future. Schwert (1989) suggests that market volatility reflects uncertainty about future cash flows and discount rates. However, he does not find evidence supporting his argument since during his sample period volatility rises after the beginning of recessions. Campbell, Lettau, Malkiel, and $\mathrm{Xu}$ (2001) find that stock volatility at a market, industry, and firm level helps to predict GDP growth during the post-war period. Goyal and Santa-Clara (2003) report a positive relation between average stock variance, that is largely idiosyncratic, and future market returns. However, they do not analyze the relation between this measure of risk and future real activity. More recently, Fornari and Mele (2011) show that a slowly changing measure of stock market volatility that captures the long run uncertainty in the financial market explains future trends of economic activity. ${ }^{2}$ Moreover, this measure of stock market volatility, together with the term structure spread, anticipate all National Bureau of Economic Research recession episodes, including the recent financial and credit crisis. In addition, Chauvet, Senyuz, and Yoldas (2011) report that the long-run component of financial volatility, in the sense of Adrian and Rosenberg (2008) but extracted from the realized volatilities of the market, industry portfolios, and the 10-year zero coupon Treasury bond returns, helps in predicting economic activity. ${ }^{3}$

\footnotetext{
${ }^{2}$ Fornari and Mele (2011) justify their findings following the theoretical framework of Mele (2007, 2008), who shows the countercyclical and asymmetric nature of volatility in recessions and expansions. ${ }^{3}$ In related literature, Andreou, Ghysels, and Kourtellos (2010) employ implied volatility as a predictor of economic activity and Backus, Chernov, and Martin (2011) employ equity index options to quantify the distribution of consumption growth disasters. These authors show that options suggest smaller probabilities of extreme outcomes than have been estimated from macroeconomic data. It is important to
} 
Finally, Nieto and Rubio (2011), using a consumption-based parametric approach for measuring the uncertainty embedded in financial prices, also predict real activity. Specifically, they use the volatility of alternative consumption-based stochastic discount factor specifications as a measure of uncertainty and find that this measure is able to forecast economic growth at both short and long horizons. ${ }^{4}$

This paper employs a much simpler approach to investigate the predictability of real activity. In particular, we propose the Hansen-Jagannathan (HJ hereafter, 1991) volatility bound as the predictor. Given a set of portfolio returns and the average riskfree rate for the corresponding sample, we compute the volatility bound with a rolling window of five years of past data. We show that this model-free volatility bound is a powerful predictor of future economic growth for both in-sample and out-of-sample contexts. From a practical point of view, it is important to notice that this approach requires only financial market returns. This implies that our forecasting measure can be used in real time when employing an out-of-sample forecasting framework. This strongly contrasts with the highly parameterized approach followed by Nieto and Rubio (2011), in which the stochastic discount factor is the marginal rate of substitution of consumption. However, it should also be pointed out that both approaches rely on a volatility bound. In the previous paper, the estimation of the preference parameters is carried out by imposing the restriction that the stochastic discount factors are inside the HJ volatility frontier. Additionally, and given this restriction, the squared pricing errors of 10 size-sorted portfolios are minimized obtaining volatility bounds that are precisely

point out that not only lagged market returns and volatility have been employed as leading indicators of economic activity. Naes, Skleltorp, and Arne-Odegaard (2011) report a strong relation between stock market liquidity and the business cycle.

4 The authors also show some power in predicting stock market returns at relatively long horizons. Although they show some predicting capacity at short horizons, the predictability of stock market returns is much weaker than at long horizons. The current paper does not address the issue of predicting stock returns. For recent literature on predicting future stock market excess returns, see, among many others, Campbell and Yogo (2006), Cochrane (2008), Goyal and Welch (2008), Brennan and Taylor (2010), Ferreira and Santa-Clara (2011), and Cochrane (2011). 
on the frontier. In this paper, the approach is not only much more relevant from a practical point of view, but it is a much simpler way of obtaining a bound that lies on the frontier. Of course, the particular combination of the mean and variance of the corresponding stochastic discount factor is always different in all cases.

The second contribution of the current paper is to explain why size is the key issue when forecasting real activity using the volatility bound. Changes in economic conditions represented by better/tighter credit conditions generate strong asymmetric effects on size-sorted portfolios. In particular, the asymmetric sensitivities of returns and volatilities of small and large companies to credit scenarios through the business cycle explain our findings. It seems that these asymmetries in both time-series and on the cross-section of size-sorted portfolio returns are the responsible of the forecasting power of the resulting HJ volatility bound. Other alternative sorting procedures based on book-to-market, momentum, or dividend yield do not show these asymmetric sensitivities relative to different credit scenarios. It turns out that their lack of sensitivity to credit conditions significantly limits the forecasting capacity of output growth from combining these portfolios in the particular proportions suggested by the HJ volatility bound.

Finally, it should be recognized that the HJ bound is the maximum Sharpe ratio; thus our measure includes not only excess market returns but also information about correlation or exposure to common shocks and market volatility. Hence, we also investigate the source of forecasting ability by analyzing the predicting ability of the components of the bound. We find that predictability crucially depends on the interaction between the numerator and denominator of the bound of size-sorted portfolios, and not on any particular component. Once again, this interaction effect is not observed for any other sorting procedure. 
The remainder of the paper is organized as follows. Section 2 describes the data employed in the analysis. Section 3 presents the main in-sample and out-of-sample predictability results using size-sorted portfolios. Section 4 compares the predicting ability of the HJ measure with respect to standard state variable predictors, and competing measures of financial uncertainty. Section 5 discusses the forecasting evidence using alternative sorting procedures, and Section 6 explains the reasons underlying the forecasting capacity of the bound when using size-sorted portfolios, and not alternative sorting procedures. Section 7 concludes with summary and final remarks.

\section{Data}

Most stock market data are from Kenneth French's website. We obtain monthly data from January 1927 to December 2010 for the market return $\left(R_{m}\right)$, the risk-free rate $\left(R_{f}\right)$, the small-minus-big $(S M B)$ and high-minus-low $(H M L)$ Fama and French (1993) risk factors, and 10 value-weighted size-, book-to-market-, momentum-, and dividend yield-sorted equity portfolios. Additionally, we collect data for the daily 100 size-bookto-market value-weighted portfolios from July 1963 to December 2010.

The price-dividend ratio in $\operatorname{logs}(P D)$ is computed from the original series on Robert Shiller's website. Additionally, yields for the 10-year government bond, and Moody's Baa Corporate Bond series are obtained from the Federal Reserve Statistical Release. We then compute two state variables based on these interest rates: a term structure slope (Term), computed as the difference between the 10-year government bond and the risk free rate, and a default premium (Default) that is the difference between Moody's yield on Baa Corporate Bonds and the 10-year government bond yields. All these series are collected from January 1959 to December 2010. 
Given the real activity forecasting evidence from aggregate illiquidity reported by Naes, Skjeltorp, and Arne-Odegaard (2011) at quarterly frequency, we also use a market-wide illiquidity indicator (Illiq) based on the aggregate illiquidity ratio proposed by Amihud (2002). This is the ratio of the absolute daily return over the dollar volume for a given stock, which is closely related to the notion of price impact. This measure is averaged monthly and across all available stocks to obtain the market-wide illiquidity measure for each month in the sample. As in Naes, Skjeltorp, and Arne-Odegaard (2011), we demean the series relative to a two-year moving average of the series. ${ }^{5}$

Daily data on VIX is obtained from January 1990 to December 2010 from CBOE. This series is augmented from January 1986 to December 1989 using VXO also from CBOE. ${ }^{6}$ In both cases, we employ the last day of the corresponding month to create a final monthly option-implied volatility series from January 1986 to December 2010.

We collect three alternative measures of monthly macroeconomic growth. We obtain nominal consumption expenditures on nondurable goods and services from the Table 2.8.5 of the National Income and Product Accounts (NIPA) available at the Bureau of Economic Analysis. Population data are from NIPA's Table 2.6 and the price deflator is computed using prices from NIPA's Table 2.8 .4 with the year 2000 as its basis. All this information is used to construct monthly seasonally adjusted real per capita consumption expenditures on nondurable goods and services $(\Delta C)$ from January 1959 to December 2010. Monthly data of the industrial production index (IPI) are

\footnotetext{
${ }^{5}$ We thank Yakov Amihud for kindly providing his data from January 1965 to December 1996. We update his measure from January 1997 to December 2008 using daily data from CSRP on all individual stocks with enough data within a given month. At least 15 observations of the ratio within the considered month are required for asset $j$ to be included in the sample. An exception has been made for September 2001 requiring at least 12 observations in this case. The main advantage of Amihud's illiquidity ratio is that it can be easily computed using daily data during long periods. Moreover, Hasbrouck (2009) shows that, at least for US data, Amihud's ratio better approximates Kyle's lambda relative to competing measures of illiquidity.

${ }^{6}$ VIX is the volatility index for the S\&P 500 index, while VXO refers to the S\&P 100 index.
} 
downloaded from the Federal Reserve, with series identifier G17, IP Mayor Industry Groups from January 1927 to December 2010. Lastly, the monthly growth rate of gross domestic product $(G D P)$ is obtained from the Macroeconomic Advisers' web page. ${ }^{7}$ These data are available from April 1992 to December 2010. Finally, we also collect the quarterly cross-sectional dispersion measures for quarterly forecasts for $G D P$ from the Survey of Professional Forecasters'web page which is available from the fourth quarter of $1968 .^{8}$

\section{In-Sample and Out-of-Sample Predictability of Real Activity with the Volatility of the HJ Bound and Size-Sorted Portfolios}

\subsection{The HJ Volatility Bound}

We estimate the monthly $\mathrm{HJ}$ volatility bound of the model-free stochastic discount factor with overlapping sub-periods of five years of monthly data from the 10 valueweighted size-sorted equity portfolios using,

$$
\sigma(M) \geq\left[\left(1_{N}-E(M) E(R)\right)^{\prime} V^{-1}\left(1_{N}-E(M) E(R)\right)\right]^{1 / 2}
$$

where $M$ is the stochastic discount factor satisfying the first-order pricing equations,

$$
\begin{gathered}
\left.I=E_{t} \mid M_{t+1} R_{j t+1}\right\rfloor, \\
E_{t}\left[M_{t+1}\right]=1 / R_{f t+1},
\end{gathered}
$$

where $1_{N}$ and $E(R)$ are the $N$-vectors of ones and average gross returns, respectively; $V^{-1}$ is the inverse of the variance-covariance matrix of returns; and $R_{f}$ is the gross risk-free rate. The monthly estimated volatility corresponds to the average level of the risk-free interest rate for each of the five-year sub-periods. Unlike the work by Nieto

\footnotetext{
${ }^{7}$ http://www.macroadvisers.com/content/MA_Monthly_GDP_Index.xls.

${ }^{8}$ http://www.phil.frb.org/research-and-data/real-time-center/spf-forecast-dispersion.cfm.
} 
and Rubio (2011), this procedure does not depend on any particular consumption-based stochastic discount factor specification, so the potential predictive relation does not depend on any given consumption dynamics.

Table 1 contains the descriptive statistics of the volatility bound estimated from 1927 to 2010 . The average volatility bound is 0.504 with a volatility of 0.148 , and positive skewness and high excess kurtosis. ${ }^{9}$ The autocorrelation of the volatility bound is also high and equal to 0.971 suggesting, as expected, that the bound is quite persistent over time. It is useful to discuss the implications of this autocorrelation for the empirical results we report below. As discussed in the introduction, the estimated volatility bound is our main predictor variable in typical forecasting regressions of future output growth on the volatility bound and (possibly) other competing predictors. The conventional inference in a predictive regression assumes that the explanatory variable is stationary. In that case, first-order asymptotics implies that the $t$-statistic for testing the forecasting ability of the predictor is approximately standard normal in large samples. However, the null distribution of the $t$-statistic can be dramatically different when the predictor is nonstationary, since the distribution is discontinue at the point that autocorrelation equals one, and the innovations in the predictor and in the variable to be predicted are correlated. There is ample simulation evidence and analytical studies on the poor approximation of the large-sample theory to the actual finite sample showing large size distortions. $^{10}$

Two possible solutions have been adopted in the case of highly persistent predictors. One approach is based on the exact finite sample theory as in Stambaugh (1999), and many other following papers like Lewellen (2004), Amihud and Hurvich (2004), and Amihud, Hurvich, and Wang (2009). The idea behind this approach is to

\footnotetext{
${ }^{9}$ The Sharpe ratio for the market as a whole turns out to be 0.113 for the same sample period.

${ }^{10}$ See Elliot and Stock (1994).
} 
eliminate the noise produced by the correlation among innovations. Unfortunately, the problem in practice is that it is not possible to certainly know whether a time series has or not a unit root and, therefore, the true distribution of the tests is unknown.

The second approach is based on the local-to-unity asymptotics, where the predictor is assumed to be autoregressive with a root near to unity. ${ }^{11}$ Specifically, the largest autoregressive root is modeled as $\rho=1+c / T$ with $c$ a fixed constant, and $T$ the number of observations. ${ }^{12}$ Deviations from the unit root are measured by the parameter $c$, which is the responsible of inducing non-centrality in the limiting distribution. This device allows the predictor to be stationary but nearly integrated when $c<0$. The larger the parameter $c$, in absolute value, the less persistent is the predictor. If this uncertainty about the deviations from the unit root is ignored, as in conventional tests, the asymptotic size exceeds the nominal level. Moreover, the correlation between the innovations of the predictor and the dependent variable acts as a power parameter in the limiting distribution. In fact, if this correlation is zero, the $t$-statistic is asymptotically normal distributed. Therefore, when the correlation is sufficiently low and/or the unit root deviation parameter is sufficiently high, the distortion in test size is unappreciable. Campbell and Yogo (2006) derive a pretest for determining if the predictor is sufficiently stationary, for a given level of correlation, such that the conventional critical values can be applied and tabulate the results. In particular, they tabulate the values of $c$ for which the size of the right-tailed $t$-test exceeds $7.5 \%$, for selected values of the correlation between the residuals. Their tabulated values can therefore be used to construct a pretest to decide whether inference based on the conventional $t$-test is sufficiently reliable. Specifically, they indicate that, independently of the

\footnotetext{
${ }^{11}$ See Stock (1994).

12 Torous, Valkanov, and Yan (2004) obtain the null asymptotic distribution for the $t$-statistic under this framework.
} 
autocorrelation of the predictor, the size of the test is less than $7.5 \%$ when the correlation between the innovations is equal or less than 0.125 in absolute value. ${ }^{13}$

In order to know if standard inference can be applied to our predicting exercise, we compute the serial correlation of our proposed predictor, the HJ volatility bound, and the correlation between the residual from the predictive regression and an $\operatorname{AR}(1)$ process for the predictor. That is, we estimate the following ordinary least squares (OLS) regression model,

$$
\begin{gathered}
\Delta I P I_{t, t+\tau}=\alpha+\beta \sigma_{t}(M)+\varepsilon_{t+\tau}, \\
\sigma_{t+\tau}(M)=\theta+\rho \sigma_{t}(M)+u_{t+\tau},
\end{gathered}
$$

where $\Delta I P I_{t, t+\tau}$ is the growth of industrial production at horizons of one, three, six, 12, and 24 months calculated as $\Delta I P I_{t, t+\tau}=\ln \left(I P I_{t+\tau} / I P I_{t}\right)$, and $\sigma_{t}(M)$ is the volatility bound of the stochastic discount factor available at month $t$ that is estimated with five years of monthly data up to month $t$ and 10 size-sorted portfolios. We compute the correlation between the residuals from the two equations, $\operatorname{Corr}\left(\hat{\varepsilon}_{t+\tau}, \hat{u}_{t+\tau}\right)$, which is displayed in the second column of Table 1 for the alternative forecasting horizons analyzed in the paper. Despite the apparently high level of persistence of 0.971 , the correlations between the innovations in IPI and the HJ volatility bound are near to zero for all horizons between 1 and 12 months, ranging from -0.014 to 0.008 respectively. Even at the 24-month horizon the correlation is lower than 0.125 indicating that standard asymptotic distributions can be applied for testing the significance of the predictor. $^{14}$

\footnotetext{
${ }^{13}$ Campbell and Yogo (2006) also propose a new Bonferroni test of stock return predictability, within the local-to-unity asymptotics, which is more efficient than the previous available test due to Cavanagh, Elliot, and Stock (1995).

${ }^{14}$ In the case of the predictive regression at the longest horizon, it should be recognized that the residuals are much higher (serially) correlated due to the overlapping nature of the long horizon data. Conventional inference employs the Newey-West (1987) autocorrelation-robust standard error. This is also the procedure followed in our empirical approach. Torous, Valkanov, and Yan (2004) derive the limiting
} 
Figure 1 show this rolling-window HJ volatility bound and the National Bureau of Economic Research's recession bars for the period from 1931 to 2010. It shows how the bound tends to increase before macroeconomic recessions, reaching its historical peak well before and during the recent financial turmoil. Although the peaks of the bound tend to occur during the corresponding recession months, the volatility of the stochastic discount factor always increases before the start of a recession. Our paper formalizes the evidence suggested by Figure 1, and discusses the reasons behind the forecasting ability when employing size-sorted portfolios.

\subsection{In-Sample Predictability with the HJ Volatility Bound}

We now proceed to analyze the predicting capacity of the bound using the 10 sizesorted portfolios. Panel A of Table 2 reports the results from the following in-sample predictive OLS autocorrelation-robust standard error regressions:

$$
\begin{gathered}
\Delta I P I_{t, t+\tau}=\alpha+\beta \sigma_{t}(M)+\varepsilon_{t+\tau}, \\
\Delta I P I_{t, t+\tau}=\alpha+\beta_{1} \Delta I P I_{t, t-\tau}+\beta_{2} \sigma_{t}(M)+\varepsilon_{t+\tau}
\end{gathered}
$$

where the first equation is the key univariate predictive regression we analyze in the paper, and the second equation takes into account that serial correlation in industrial production growth is expected since we make multi-step ahead predictions. This suggests that the forecasting regressions should also include lagged values of the dependent variable.

Each row of all panels of Table 2 corresponds to a particular prediction horizon from one to 24 months. Although we employ industrial production growth as the relevant measure of real activity, Panel B reports similar evidence using GDP and

distribution for the robust $t$-statistic in a local-to-unity framework and they show that, as in the case of the one-period horizon, it depends on the correlation between innovations of the variable to be predicted and the predictor. 
consumption growth instead of IPI growth. Given data restrictions on some of the state variables used later, we run these predictive regressions between January 1965 and July 2010, although Panel C contains evidence for alternative sub-periods. ${ }^{15}$

The top left of Panel A reports the key results of the paper. There is a negative and significant relationship between the HJ volatility bound and future industrial production growth. Both the magnitude of the coefficients (in absolute value) and the $\mathrm{R}^{2}$ value increase considerably with the time horizon, with $\mathrm{R}^{2}$ as high as (approximately) 20 percent at the 24-month horizon. If we interpret $\sigma_{t}(M)$ as a measure of the financial uncertainty embedded in stock prices, these results show that higher uncertainty has a negative and significant impact on future real activity. ${ }^{16}$ Therefore, our measure of uncertainty conveys information about future economic growth.

The autoregressive structure of IPI growth is confirmed for horizons of one, three, and six months. However, the coefficients associated with the HJ volatility bound remain negative and statistically significant in all cases. In fact, these coefficients are very similar to those reported above. Therefore, although the inclusion of the lagged dependent variable helps predict real activity, lagging the dependent variable does not seem to have any effect on our previous conclusions regarding the importance of the HJ volatility bound as an ex ante uncertainty predictor of economic cycles.

Our previous discussion on local-to-unity framework suggests that we may employ the conventional standard aysmptotics when testing the significance of the volatility bound as a predictor. In any case, we provide further evidence using the biascorrected $t$-statistic proposed by Amihud and Hurvich (2004), and Amihud, Hurvich, Wang (2009) in all previously estimated forecasting regressions. The negative and

\footnotetext{
${ }^{15}$ The only exception corresponds to the forecasting results using GDP growth where the sample period goes from April 1992 to December 2010. It should be recalled that we use monthly data in all panels. ${ }_{16} t$-statistics are reported below the estimated coefficients.
} 
significant relation between the volatility bound and future real activity is maintained for all horizons. In particular, the adjusted $t$-statistic ranges from -2.20 to -3.00 for the one and 24 month horizons respectively in the univariate regression, and from -1.97 to -2.77 when we add the lagged IPI growth in the regressions. ${ }^{17}$

Panel B of Table 2 displays the forecasting evidence using GDP and consumption growth as the variables to be predicted. In both cases, there is significant evidence of the HJ volatility bound forecasting future macroeconomic activity. The results are particularly striking in the case of consumption growth. The bound, as a measure of financial uncertainty, seems to contain information for future consumption growth. The volatility bound is strongly and negatively correlated with future aggregate consumption.

Panel C of Table 2 contains similar evidence for three alternative sub-periods using IPI growth as a measure of real economic activity. The previous empirical evidence is maintained for the full period from January 1931 to December 2010, but it seems to be especially important for the sub-period between January 1965 and December 1987. The higher volatility of macroeconomic variables in the US market before the great moderation years experienced between the mid eighties and 2007 may explain the stronger predictive ability of the bound during the first sub-period.

\subsection{Out-of-Sample Predictability with the HJ Volatility Bound}

The predicting tools employed so far examine the ability of the predictors had we been able to use the coefficients estimated by the full-sample regressions. We now consider tests designed to generate more closely actual real time forecasts. We employ two

\footnotetext{
${ }^{17}$ These authors suggest a regression method for hypothesis testing in predictive regressions in which the independent variables are persistent and their innovations are correlated with the dependent variable. The authors' simulations show that their adjustment outperforms other bias correction methods, such as those suggested by Stambaugh (1999) and Lewellen (2004), and other bootstrapping methods. The detailed results are available from the authors upon request.
} 
alternative statistics for testing the out-of-sample accuracy of two competing models: the $t$-test proposed by Diebold and Mariano (1995) and the $F$-statistic of McCracken (2007). In our case, the two compared models are always nested. The restricted model contains only one predicting variable. On the other hand, the unrestricted model contains such a variable and the HJ volatility bound estimated with 10 size-sorted portfolios.

We now briefly describe this methodology. The total sample period contains $T+$ $P$ observations, where the initial in-sample estimation period employs information from 1 to $T$, and the out-of-sample forecasting period goes from $T+\tau$ to $T+P, \tau$ being the forecasting horizon. At each forecasting period $t=T+\tau, \ldots, T+P$, we estimate the two competing nested models using information up to the previous $\tau$ periods, generate the prediction, and compute the forecasting error. More formally, the restricted model is

$$
Y_{s}=\beta_{0}^{R}+\beta_{1}^{R} X_{s-\tau}+u_{R s}, \quad s=\tau+1, \ldots, t-\tau .
$$

The prediction under the restricted model is

$$
\hat{Y}_{R t}=\hat{\beta}_{0}^{R}+\hat{\beta}_{1}^{R} X_{t-\tau},
$$

and the prediction error will be

$$
\hat{u}_{R t}=Y_{t}-\hat{Y}_{R t} .
$$

Similarly, the unrestricted model that includes the HJ volatility bound, the next period prediction and forecasting error are

$$
\begin{gathered}
Y_{s}=\beta_{0}^{U}+\beta_{1}^{U} X_{s-\tau}+\beta_{2}^{U} \sigma_{s-\tau}(M)+u_{U s}, \quad s=\tau+1, \ldots, t-\tau, \\
\hat{Y}_{U t}=\hat{\beta}_{0}^{U}+\hat{\beta}_{1}^{U} X_{t-\tau}+\hat{\beta}_{2}^{U} \sigma_{t-\tau}(M), \\
\hat{u}_{U t}=Y_{t}-\hat{Y}_{U t} .
\end{gathered}
$$


We next compute the vector of loss differentials, denoted $d$, that compares the two square errors at each month $t$ and the mean squared forecasting error (MSE) for each model:

$$
\begin{array}{r}
d_{t}=\hat{u}_{R t}^{2}-\hat{u}_{U t}^{2}, t=T+\tau, \ldots, T+P, \\
M S E_{R}=(P-\tau+1)^{-1} \sum_{t=T+\tau}^{T+P} \hat{u}_{R t}^{2}, \\
M S E_{U}=(P-\tau+1)^{-1} \sum_{t=T+\tau}^{T+P} \hat{u}_{U t}^{2} .
\end{array}
$$

The two statistics for testing equal forecasting accuracy have the null that the loss differentials are zero, on average. The Diebold-Mariano (1995) statistic is a $t$-test expressed as

$$
M S E-t=(P-\tau+1)^{-1 / 2} \frac{\bar{d}}{\sqrt{\hat{S}_{d}}}
$$

where $\bar{d}=(P-\tau+1)^{-1} \sum_{t=T+\tau}^{T+P} d_{t}$ and $\hat{S}_{d}$ is a consistent estimator of the variance of the loss differential that admits heteroskedasticity and autocorrelation. We employ the Newey-West (1987) specification and, following Clark and McCracken (2011), a lag length of $k=1.5 \cdot \tau$. Hence

$$
\hat{S}_{d}=\sum_{j=-k}^{k}\left(\frac{k-|j|}{k}\right)(P-\tau-j+1)^{-1} \sum_{t=T+\tau}^{T+P}\left(d_{t}-\bar{d}\right)\left(d_{t-j}-\bar{d}\right)
$$

The McCracken (2007) statistic is an F-test given by

$$
M S E-F=(P-\tau+1) \frac{M S E_{R}-M S E_{U}}{M S E_{U}} .
$$

It must be noted that the loss differentials are measured with an error that is due to the fact that the beta coefficients are unknown. This implies that the exact distribution 
of both statistics is also unknown and that the asymptotic distribution can only be obtained under restrictive assumptions that include non-nested models. ${ }^{18}$ As previously pointed out, this paper compares nested models. For this case, Clark and McCracken (2011) suggest deriving the asymptotic distribution by a fixed regressor bootstrap, and they show that the test statistics based on the proposed bootstrap have good size properties and better finite-sample power than alternative bootstraps. This method is based on the wild fixed regressor bootstrap developed by Goncalves and Killian (2004) but adapted to the multi-step framework of out-of-sample forecasts. To implement this method, we use the followings steps.

1. We estimate both the restricted and unrestricted models using the full sample period and we compute the residuals from the unrestricted model:

$$
\hat{u}_{U t}=Y_{t}-\hat{\beta}_{0}^{U}+\hat{\beta}_{1}^{U} X_{t-\tau}+\hat{\beta}_{2}^{U} \sigma_{t-\tau}(M), \quad t=1+\tau, \ldots, T+P .
$$

2. We assume and estimate an MA $(\tau-1)$ process to capture the implicit serial correlation in the residuals from a $\tau$-step-ahead forecast,

$$
u_{U t}=\varepsilon_{t}+\theta_{1} \varepsilon_{t-1}+\ldots,+\theta_{\tau-1} \varepsilon_{t-(\tau-1)}, \quad t=1+\tau, \ldots, T+P
$$

3. We simulate a sequence of independent and identically distributed $N(0,1)$ random variables denoted by $\eta_{t}$ and generate artificial residuals by using the estimates of the MA process:

$$
u_{U t}^{*}=\eta_{t} \hat{\varepsilon}_{t}+\hat{\theta}_{1} \eta_{t-1} \hat{\varepsilon}_{t-1}+\ldots,+\hat{\theta}_{\tau-1} \eta_{t-(\tau-1)} \hat{\varepsilon}_{t-(\tau-1)}, \quad t=2 \tau, \ldots, T+P
$$

4. We simulate an artificial series of the dependent variable using the artificial residual and imposing the null hypothesis:

$$
\hat{Y}_{t}^{*}=\hat{\beta}_{0}^{R}+\hat{\beta}_{1}^{R} X_{t-\tau}+u_{U t}^{*}, t=2 \tau, \ldots, T+P .
$$

\footnotetext{
${ }^{18}$ See West (1996) and Clark and McCracken (2001) for a discussion.
} 
5. We compute both the MSE $t$-statistics and MSE $F$-statistics using these artificial data as if they were the original data.

6. Repeat steps $3-55,000$ times and the $p$-value is the percentage of times the simulated statistic is greater than the real statistic.

Panel D of Table 2 contains the initial out-of-sample results where we test for the absolute out-of-sample performance of the volatility bound, and its relative performance with respect to the lagged $I P I$ growth as the competing predictor. In the first case, the unrestricted model is given by expression (4), while the restricted model is just a forecasting regression of future output growth in a constant,

$$
\Delta I P I_{t, t+\tau}=\alpha+\varepsilon_{t+\tau}
$$

In the second case, the unrestricted model is given by equation (5), and the restricted model is the $\mathrm{AR}(1)$ base case,

$$
\Delta I P I_{t, t+\tau}=\alpha+\beta_{1} \Delta I P I_{t, t-\tau}+\varepsilon_{t+\tau}
$$

The out-of-sample results are similar in both cases. The empirical results from the left box of Panel D show that the HJ volatility bound is a strong out-of-sample predictor of future growth. The relative mean squared error, $R M S E=M S E^{U} / M S E^{R}$, is less than one for all horizons except for the longest horizon of 24 months, and the null hypothesis of equal forecasting accuracy is rejected for all horizons from one to 12 months. Below each of the test statistics employed, we report the corresponding $p$-value obtained through the fixed regressor bootstrap explained above. These results imply that the inclusion of the bound improves the forecasting capacity of a constant. Similarly, when we include the lagged IPI growth as the competing predictor, the economic and statistical results are maintained, although the RMSE is slightly closer to one relative to the first case. The volatility bound significantly improves the out-of-sample forecasting ability of the lagged IPI growth as the competing predictor. 


\section{Competing In-Sample and Out-of-Sample Predictors of Real Activity}

\subsection{The Competing Predictors}

We now investigate how robust our forecasting results are to competing predictor variables of real activity. We consider predictors related to interest rates, stock market returns, and illiquidity.

The term spread, measured as the difference between the interest rates on long and short maturity government debt, is probably the most common financial leading indicator of real activity. Among many others, Estrella and Hardouvelis (1991), Estrella and Mishkin (1998), Stock and Watson (2003), Ang, Piazzesi, and Wei (2006), and Fornari and Mele (2011) show the significant predictive content of the spread for production growth, including its capacity to forecast a recession indicator in probit regressions. Additionally, there is a growing body of literature exploring the transmission of credit conditions into the real economy. Among recent papers, Mueller (2009) and Gilchrist, Yankov, and Zakrajsek (2009) show the forecasting power of the term structure of credit spreads for future output growth. These authors argue that there is a pure credit component orthogonal to macroeconomic conditions that accounts for a large part of the predicting capacity of credit spreads.

Moreover, as long as stock prices equal the expected discounted value of future earnings and dividends, stock returns should also be useful in forecasting output growth. This is the insight of Fama $(1981,1990)$. On top of that, given the well-known evidence of the aggregate dividend yield being a powerful predictor of future market excess returns, as discussed recently by Cochrane (2011), the price-dividend ratio becomes a potential state variable for forecasting real activity. Finally, Naes, Skjeltorp, and ArneOdegaard (2011) argue that stock market liquidity tends to dry up before a crisis in the real economy. In fact, they show that measures of stock market liquidity contain leading 
information about future economic growth, even after controlling for other financial leading indicators. ${ }^{19}$

\subsection{In-Sample Predictability with Competing Predictors}

We next employ all five variables discussed above and compare their in-sample predicting ability with that of the HJ volatility bound as estimated with 10 size-sorted portfolios. We run the following predictive OLS autocorrelation-robust standard error regressions with individual predictors and with pairs of predictors that always include the HJ bound:

$$
\Delta I P I_{t, t+\tau}=\alpha+\beta_{1} \sigma_{t}(M)+\beta_{2} X_{t}+\varepsilon_{t+\tau}
$$

where $X_{t}$ is either the market return, the log of the price-dividend ratio, the default spread, the term spread, or the Amihud ratio as a proxy for market-wide illiquidity.

The in-sample results are reported in Panel A of Tables 3.a to 3.e where each case corresponds to a particular forecasting horizon from one to 24 months. Independently of the alternative state variable employed and forecasting horizon, the HJ volatility bound has always a negative and highly significant relation with future IPI growth. It is especially relevant the systematic increase in the $\mathrm{R}^{2}$ once we add the volatility bound in regression (16). Hence, our forecasting relation is systematically estimated with higher precision once we add the volatility bound.

At the one-month horizon, all state variables present some evidence of predictability, except the stock market return. All predictors present the expected signs. The term spread coefficient is positive, while the rest of the state variable estimators have the theoretically correct negative sign. Note that increases in the default spread, and market-wide illiquidity signal a higher degree of uncertainty, and we also know that

\footnotetext{
${ }^{19}$ The popular stock market volatility is analyzed in the section dealing with competing measures of financial uncertainty.
} 
increases in the dividend yield forecast future positive market excess returns, which implies that increases in the price-dividend ratio should predict negative market returns and a negative impact on real activity. Once we combine on an individual basis the HJ volatility bound with the rest of the predictors, it turns out that the coefficient associated with the price-dividend ratio is estimated with much more precision. On the other hand, this result does not seem to hold for the term and market-wide illiquidity variables. It is especially relevant the combined effects of the HJ bound and the default spread; the $\mathrm{R}^{2}$ value at just the one-month horizon is 9.38 percent.

At the three-month horizon, all predictors seem to be individually significant and with the correct sign. In the combined regressions, the higher $\mathrm{R}^{2}$ statistics are obtained when adding the price-dividend ratio, or the default spread to the HJ volatility bound. The regression with the HJ bound and the price-dividend ratio presents an $\mathrm{R}^{2}$ of 15.5 percent.

Finally, for all other longer horizons, the results are similar, except that the term spread becomes much more relevant in forecasting output growth and the default spread loses its significant predicting ability. Hence, the combination of the HJ volatility bound with either the stock market return, the price-dividend ratio, or the term spread seems to be the appropriate strategy for predicting future production growth at long horizons. At the six-month horizon the highest $\mathrm{R}^{2}$ is observed when combining the $\mathrm{HJ}$ bound with the price-dividend ratio, while the combinations of the volatility bound with the term spread have the highest $\mathrm{R}^{2}$ statistics at the 12- and 24- month horizons. At the longest horizon, the HJ bound and term spread explain 28.3 percent of the variability of future production growth. To conclude, the default spread conveys information about future economic growth at relatively short horizons, while the term spread has predicting 
capacity at longer horizons. In all cases, the HJ volatility bound calculated with 10 sizesorted portfolios remains a strong predictor of real activity. ${ }^{20}$

\subsection{Out-of-Sample Predictability with Competing Predictors}

The out-of-sample results are reported in Panel B of Tables 3.a to 3.e where each case, as before, corresponds to a particular forecasting horizon from one to 24 months. The first row for each forecasting horizon shows the relative mean squared error, RMSE. Recall that when the RMSE is less than one, the inclusion of the HJ volatility bound as an additional predictor improves the forecasting capacity with respect to any of the competing standard predictors. As in Table 2, below each of the test statistics employed, we report the corresponding $p$-value obtained through the fixed regressor bootstrap of Clark and McCracken (2011). The empirical evidence is quite conclusive. Most of the time, we show that the inclusion of the HJ bound significantly improves the predicting capacity of the model. The RMSE is practically always less than one, and the $p$-values tend to be very low. It turns out that this is the case independently of the forecasting horizon. The only variable that competes on a similar basis regarding its capacity to predict real activity is the term spread. For horizons of one, three, and six months the null of no difference between the forecasting errors of the two models is not rejected. For horizons of 12 and 24 months, the RMSE is greater than one and the null is rejected, indicating that the model including only the term spread has better out-of-sample performance. Therefore, the term spread becomes a better forecaster the longer the

\footnotetext{
${ }^{20}$ The empirical results remain the same when we include the lagged IPI growth in the previous multiple forecasting regressions. In these multiple-predictor regressions, we also employ biased-adjusted $t$-statistic proposed by Amihud, Hurvich, and Wang (2009) using a diagonal matrix for the autoregressive estimated coefficients. As in the case of simple forecasting regressions, the adjusted $t$-statistic associated with the volatility bound is $-2.27,-3.28,-3.24,-1.72$, and -2.24 for one, three, six, 12, and 24.month horizons respectively when we add the stronger competitor for each particular horizon. They are the default spread, dividend yield, and term spread respectively depending upon the horizon analyzed in the regressions. All detailed results are available from the authors upon request.
} 
predicting horizon. Note that this is consistent with the in-sample results contained in Panel A of Table 3. We conclude that the volatility bound using 10 size-sorted portfolios is a strong out-of-sample predictor of future real activity relative to well known competing predictors. The uncertainty embedded in stock prices of size-sorted portfolios is a powerful indicator of future economic growth.

\subsection{Other Measures of Uncertainty as Predictors of Real Activity}

Another relevant issue is related to the comparison between the HJ volatility bound, as a measure of financial uncertainty, with traditional competitors like stock market volatility or VIX. We now provide evidence regarding the forecasting ability relative to these measures and others, less conventional measures, like idiosyncratic risk, the volatility of the SMB Fama-French risk factor, and the cross-sectional dispersion measures for quarterly forecasts for $G D P$ from the Survey of Professional Forecasters. We use two measures of cross-sectional dispersion. Dispersion measure D2 is the difference between $75^{\text {th }}$ percentile and $25^{\text {th }}$ percentile of the forecasts for GDP divided by $G D P$ growth. Dispersion measure D3 is percent log-difference between the $75^{\text {th }}$ percentile and the $25^{\text {th }}$ percentile of the forecasts for GDP.

As in the previous analysis with competing state variables, we now run again the following in-sample predictive OLS autocorrelation-robust standard error regressions:

$$
\Delta I P I_{t, t+\tau}=\alpha+\beta_{1} \sigma_{t}(M)+\beta_{2} X_{t}+\varepsilon_{t+\tau},
$$

where $X_{t}$ is now one of the alternative uncertainty measures mentioned above, and the forecasting horizons are three, six, 12 and 24 months. The shortest horizon is now 3 months given that the cross-sectional dispersion measures are only available at the quarterly frequency. 
The idiosyncratic risk refers to the average stock variance proposed by Goyal and Santa-Clara (2003), which is largely idiosyncratic. This measure avoids imposing a particular factor asset pricing model and, in our case, it is estimated either with daily or monthly data using the 100 size-book-to-market portfolios displayed in the Kenneth Frnech's web site. Similarly, the volatility of the SMB factor is also estimated with either daily or monthly data. In both cases, we employ either a rolling window of one month of daily data, or 60 months of past monthly observations. VIX, as the key reference measure of financial uncertainty, refers to the volatility given by $\mathrm{CBOE}$ at the last day of the corresponding month during the sample period.

The stock market volatility is estimated at each month as the standard deviation of monthly returns using a rolling window of five years of past observations, to be consistent with our measure of the HJ bound. As discussed in the introduction, there has been considerable recent attention to financial stock market volatility as a predictor of real activity. Fornari and Mele (2011) argue that it is important to extract the long-run component of stock market volatility when using this variable as a predictor of future growth. ${ }^{21}$ To isolate extreme financial episodes that may not be necessarily informative about the economy's future scenario, the authors propose a simple moving average of the past 12 months of absolute returns as the appropriate forecaster of real activity:

$$
\sigma_{t}\left(R_{m t}\right)=\sqrt{\frac{\pi}{2}} \cdot \frac{1}{12} \sum_{k=1}^{12}\left|R_{m t+1-k}\right|,
$$

where $\sqrt{\pi / 2}$ is a scaled factor related to the use of absolute values. We also compute this estimator of stock market volatility to provide a potentially interesting comparison with the traditional standard deviation of returns.

\footnotetext{
${ }^{21}$ See the similar arguments of Chauvet, Senyuz, and Yoldas (2011).
} 
The results are contained in Table 4 where each panel corresponds to a given forecasting horizon. The results again confirm the forecasting ability of the volatility bound on future output growth. The slope coefficient is, in all cases, negative and significantly different from zero, independently of the forecasting horizon and the additional uncertainty measure. It is especially important to notice the systematic increase of the $\mathrm{R}^{2}$ when adding the volatility bound to the forecasting regression. The combination of the bound and VIX generate the highest $\mathrm{R}^{2}$ at 3 and 6-month horizons, and it also remains high at the longest horizons. Idiosyncratic volatility and the volatility of the SMB factor are also relevant forecasters especially when we use the daily-based data estimators for relatively short horizons.

At the three-month horizon, the volatility of the stock market computed as the usual standard deviation does not present significant forecasting capacity by itself. In the combined regressions, the coefficient associated with volatility of the stock market becomes negative and estimated with more precision than in the individual regressions. This evidence suggests that the volatility bound is capturing something else than market volatility. As we will discuss later this is indeed the case. The volatility of the bound is the maximum Sharpe ratio. The predicting ability of the bound heavily depends on the interaction between the numerator and denominator rather than on the individual components of the bound. On the other hand, the market volatility estimated as in equation (17) obtains relatively better results than the traditional rolling window estimator at the shortest horizon. However, and contrary to the standard deviation, its marginal forecasting ability improvement when combined with the volatility bound is lower than the one observed with the regular measure.

Finally, we also perform the out-of-sample analysis using the Fornari-Melle measure of market volatility as the competing predictor of the volatility bound in the 
restricted regression. The RMSE for all horizons is always lower than one, ranging from 0.9589 at the 3 month horizon to 0.9742 at the longest horizon. In all cases, the test statistics show that the inclusion of the HJ volatility bound always significantly improves the predicting capacity of the stock market volatility.

We therefore conclude that the HJ volatility bound improves the in-sample forecasting ability of competing uncertainty measures, and the out-of-sample capacity of the slowly changing measure of stock market volatility.

\section{Alternative Portfolio Formation Criteria}

We now employ three additional alternative measures of the HJ volatility bound by using the returns of 10 book-to-market-, momentum-, and dividend yield-sorted portfolios and a rolling window of five years of past monthly returns. Panel A of Table 5 contains the descriptive statistics of the bound for these three sorting procedures. As for the size-sorted portfolios, all of them present positive skewness and excess kurtosis. The momentum sorting has especially high moments with a particularly high positive skewness relative to the rest of the portfolios. The correlations among the bounds are positive but low except for the correlation coefficient between the volatility bound estimated with dividend yield and book-to-market portfolios. These low correlations suggest important differences between the alternative estimated bounds. Note that the interaction between the numerator and denominator of the bound, volatility dispersion and the complex dynamic correlation behavior among the 10 portfolios in each of the four sets employed can generate a potentially different time series pattern in the HJ bounds.

We perform the forecasting regressions of equation (2) using the HJ bound estimated with the 10 portfolios of each set. Panel B of Table 5 reports the results. 
Independently of the forecasting horizon, none of the estimates of the HJ volatility bound constructed from these portfolio sets present significant predicting results. It may be the case that the dynamics induced by the different characteristics of the sorting procedures may generate a different forecasting ability of real activity. For example, it is interesting to observe that the annualized volatility dispersion between the extreme portfolios turns out to be the highest for the size-sorted portfolios. In particular, the smallest portfolio have an 18.6 percent higher annualized volatility than the portfolio of the largest stocks, while the dispersion is only 12.7 percent, 11.4 percent, and 0.9 percent for the book-to-market-, momentum-, and dividend yield-sorted portfolios. In any case, it seems that sorting procedures, and the corresponding time-varying diversification effects and sensitivities of returns and risks to the business cycle are relevant issues for forecasting production growth with volatility bounds. ${ }^{22}$

The question is: why sorting seems to be so important for predicting real activity? As pointed out before, the HJ volatility bound is the maximum Sharpe ratio. It is therefore the case that the volatility bound changes over time because the maximum Sharpe ratio varies over time. Our evidence may be driven by the expected return part of the Sharpe ratio, by the inverse of the volatility, by the interaction of the two, or by any of the two components of the volatility of the tangent portfolio. We investigates the alternative components of the maximum Sharpe ratio, $S R_{T}$, as potential sources of predictability by running forecasting regressions of future output growth on the percentage of each of the components on the absolute value of the maximum Sharpe

\footnotetext{
${ }^{22}$ Pastor and Veronesi (2009) show that the volatility of the stochastic discount factor depends on the dynamic associated with technological adoptions. In particular, they show that, once the new technology has arrived, the volatility of the stochastic discount factor tends to be flat as long as the probability of adoption is low, and it increases very rapidly as the probability increases. As with these portfolio sets, the volatility bound estimated from alternative industry-sorted portfolios does not present any significant predicting ability of future output growth.
} 
ratio. Therefore, we run forecasting regressions with four alternative independent variables:

$$
\frac{\left|E\left(R_{T}\right)-R_{f}\right|}{\left|S R_{T}\right|}, \frac{\sigma_{T}}{\left|S R_{T}\right|}, \frac{\sigma_{T}^{V a r}}{\left|S R_{T}\right|} \text {, and } \frac{\sigma_{T}^{C o v}}{\left|S R_{T}\right|}
$$

where the two last components correspond to the first and second elements of the variance of the tangent portfolio given by,

$$
\sigma_{T}^{2}=\underbrace{\sum_{j=1}^{N} \omega_{j}^{2} \sigma_{j}^{2}}_{\sigma_{T}^{\text {Var }}}+\underbrace{\sum_{\substack{j=1 \\ k=1 \\ k \neq j}}^{N} \sum_{j T}^{N} \omega_{j T} \omega_{k T} \rho j k \sigma_{j} \sigma_{k}}_{\sigma_{T}^{\text {Cov }}}
$$

The results strongly indicate that the main driver of predictability is the interaction between the numerator and the denominator of the volatility bound rather than any of its components. The only marginally significant forecasting capacity appears to be related to the components of the variance of the tangent portfolio. In particular, and only for the shortest horizons, both $\sigma_{T}^{V a r} /\left|S R_{T}\right|$ and $\sigma_{T}^{\text {Cov }} /\left|S R_{T}\right|$ present some evidence of predicting ability with the right sign. ${ }^{23}$ And, more importantly, this is the case only for the set of size-sorted portfolios. The components of the bounds for alternative sorting procedures do not present any evidence of forecasting future economic growth. It is therefore the interaction between the numerator and denominator of the bound for sizesorted portfolio the main driver of the forecasting evidence reported above.

\section{Why Size is so important for Predicting Real Activity?}

There is a consolidated literature that predicts that changing credit market conditions affect very differently small and large firms. ${ }^{24}$ Under asymmetric information, creditors

\footnotetext{
${ }^{23}$ As before, the detailed results are available from the authors upon request.

${ }^{24}$ See the fundamental arguments based on imperfect capital market theory provided by Kiyotaki and Moore (1997), and the empirical evidence reported by Pérez-Quirós and Timmermann (2000).
} 
require more collateral when lending funds to small firms than to large firms. This suggests that small firms will be more negatively affected by tighter credit conditions than large firms. Our hypothesis, in our final analysis, is that changes in economic conditions, represented by either better or tighter credit conditions will generate strong asymmetric effects on size-sorted portfolios, which will not be found in other sorting portfolio sets. In particular, small and large firms may react very differently depending upon the arrival of positive or negative credit condition news, and this asymmetric reaction should be impounded into excess expected return and risk of optimally selected size-sorted portfolios. Indeed, this asymmetric sensitivity to credit conditions within size firms should be the information contained in the HJ volatility bound that helps predicting real activity. Again, and this is the key issue, there are no reasons to find these asymmetries to credit conditions in the alternative sorted portfolios characterized by book-to-market, momentum or dividend yield.

We next document systematic differences in the dynamic behavior over the business cycle in small and large firms that are not found in other sorted portfolios. To be consistent with imperfect capital market theories, it is important to employ credit conditions to identify the business cycle variations, and then to investigate how these different credit scenarios affect our four portfolio sorts. In doing so, we simply allow the conditional distribution of returns to vary with the state of the business cycle, and then we study how the sensitivities of expected returns and risk to credit conditions depend on size, value-growth, momentum, and dividend-yield.

We employ a Markow switching model along the lines of Pérez-Quirós and Timmermann (2000). In particular, for each portfolio $i$ within each set, the parameters of the excess return and volatility equations are functions of a single latent state variable $S$, that can represent two states, $S_{t}=1$ or $S_{t}=2$ : 


$$
\begin{gathered}
R_{t+1}^{i}-R_{f t+1}=\beta_{0, S}^{i}+\beta_{1, S}^{i} D e f_{t}+\varepsilon_{t+1}^{i} \\
\varepsilon_{t+1}^{i} \sim N\left(0, h_{S t+1}^{i}\right), \ln \left(h_{S t+1}^{i}\right)=\lambda_{0, S}^{i}+\lambda_{1, S}^{i} X_{t}
\end{gathered},
$$

where $X_{t}$ is either the known default premium at time $t$ or the risk-free rate. ${ }^{25}$

We assume that the transition probabilities are constant,

$$
p^{i}=\Phi\left(\alpha_{S}^{i}\right), S=1,2
$$

where $\Phi$ denotes the cumulative density function of a standard normal variable, and the parameters to be estimated for each portfolio $i$ are

$$
\left(\alpha_{S}^{i}, \beta_{0, S}^{i}, \beta_{1, S}^{i}, \lambda_{0, S}^{i}, \lambda_{1, S}^{i}\right), S=1,2
$$

To estimate the parameters we maximize the log-likelihood function,

$$
\operatorname{Max} \sum_{t=0}^{T-1} \phi_{t+1}^{i}
$$

where the density $\phi_{t+1}$ is obtained by summing the probability weighted state densities, $g($.$) , across the two possible states,$

$$
\phi_{t+1}^{i}=\ln \left[\left(P_{1 t+1}^{i} g_{1 t+1}^{i}\right)+\left(\left(1-P_{1 t+1}^{i}\right) g_{2 t+1}^{i}\right)\right]
$$

where $g_{S t+1}^{i}=\frac{1}{\sqrt{2 \pi h_{S t+1}^{i}}} \exp \left\{\frac{-\left(R_{t+1}^{i}-R_{f t+1}-\beta_{0, S}^{i}-\beta_{1, S}^{i} D e f_{t}\right)^{2}}{2 h_{S t+1}^{i}}\right\}, S=1,2 \quad$ and $P_{S t+1}^{i}$ is the conditional probability of being in state $S=1,2$ at time $t+1$ given the information at time $t$. Finally, from the total probability theorem and the Bayes' rule, the conditional state probability of being in the state 1 can be written as

$$
P_{1 t+1}^{i}=\frac{\left(1-q^{i}\right)+\left(\left(p^{i}+q^{i}-1\right) g_{1 t}^{i} P_{1 t}^{i}\right)}{\left(g_{1 t}^{i} P_{1 t}^{i}\right)+\left(g_{2 t}^{i}\left(1-P_{1 t}^{i}\right)\right)}
$$

\footnotetext{
${ }^{25}$ In the GARCH literature is very common to add the risk-free rate as a control variable.
} 
The empirical results are reported in Table 6. For each portfolio $i$, the top and the middle blocks of the table show the mean and the variance estimated parameters with the corresponding $t$-values for testing individual significance in parenthesis. At the bottom of the table, we report the tests for symmetric coefficients between states for both the mean and variance equations. We employ the likelihood ratio test, and the corresponding $p$-values are reported below the restricted log-likelihood values.

Each panel corresponds to a particular portfolio set. Panel A contains the results using 10 size-sorted portfolios, while Panels B to D displays the results for book-tomarket, momentum, and dividend yield respectively. The reported results employ the default spread in both the mean and the variance equations. We repeat the same estimation process using the default spread in the mean equation, by itself or with other predictors, and the risk-free rate in the variance equation. In all cases the results are qualitative the same. $^{26}$

A common result is that the null hypothesis of symmetry in the volatility equation is strongly rejected for all portfolios in the four panels. This is not the case for the mean equation. The rejection of the null occurs for seven out of the 10 portfolios in panels $\mathrm{B}$ and $\mathrm{C}$, and for 6 portfolios in panel D. On the other hand, for size-sorted portfolios, symmetry in mean returns is rejected for nine out of the 10 portfolios. Especially relevant is the case of the portfolio of small stocks. This is the only portfolio in the four portfolio sets for which both the mean and the volatility react significantly and with the opposite sign depending upon the arrival of positive or negative news. The mean return increases and the volatility decreases when there is a positive default shock in state 1 , while mean return decreases and volatility increases when the credit conditions get worse in state 2. Hence, small firms' risk and expected returns are most strongly

\footnotetext{
${ }^{26}$ Results are available upon request.
} 
affected by both a negative and a positive default shocks. On the other hand, the large firms' expected returns and risk present much weaker and different state dependencies with respect to credit conditions. This introduces a large asymmetric cross-sectional response to changes in the business cycle within the size-sorted portfolios. More importantly, the asymmetric response among the 10 size deciles to changing business cycle is strikingly different from the response within alternative sorted portfolios. The estimated sensitivities to credit changing conditions in both the mean and variance equations contained in Panels $\mathrm{B}$ through $\mathrm{D}$ are different, much weaker and less significant in all other sorting procedures than under the 10 size-sorted portfolios. Therefore, we find that small firms (relative to large firms) contain the highest degree of asymmetry in their conditional return distribution across different credit scenarios. These particularly strong asymmetric responses are impounded in the optimal combination of size-sorted portfolios, so that the interaction between excess returns and risk reflected in the $\mathrm{HJ}$ volatility bound contain significant information about the future state of the economy. This can explain the strong predicting capacity that the size-based volatility bound has about future real activity.

\section{Conclusions}

The uncertainty embedded in equity portfolio returns helps predict future economic growth. This paper contributes to literature by showing that changes in the uncertainty embedded in stock returns measured by the model-free HJ volatility bound is a strong predictor of future real activity. However, data employed in the estimation of the volatility bound seem to be a key issue in properly incorporating the information that is actually relevant for predicting future economic growth. Sorting stocks on the basis of size generates a very powerful leading predictor. Alternative equity portfolio sorting 
formations lead to very different conclusions regarding the forecasting ability of the bound.

We show that the HJ volatility bound, when employing data on 10 size-sorted portfolios, generates significant predictions of real activity both in sample and out of sample. This is the case independently of the forecasting horizon, the time period, or the proxy use for measuring economic growth. Also the inclusion of the HJ bound constructed with size-sorted portfolios significantly improves the in sample and out-ofsample forecasting ability of such well-known predictors as the stock market volatility, and the default spread, and competes on similar basis with the term spread.

Given that the HJ volatility bound is the maximum Sharpe ratio, we also investigate the source of forecasting through the analysis of the individual components of the bound. We conclude that the main driver of predictability is the dynamic interaction between the numerator and denominator of the volatility bound of the sizesorted portfolios. The second contribution of the paper is to show that the information content in the asymmetric response of the size-sorted portfolios relative to the business cycle, represented by changing credit conditions, is the ultimate explanation for the systematic and strong predictability reported in this paper. The mean and variance responses of book-to-market, momentum or dividend-yield returns to changing credit conditions are weaker and less asymmetric than the responses of the size-sorted portfolios. Size is, once again, an enormous source of information for both Economics and Finance. 


\section{References}

Adrian, T., and J. Rosenberg (2008). Stock Returns and Volatility: Pricing the LongRun and Short-Run Components of Market Risk, Journal of Finance 63, 29973030

Amihud, Y. (2002). Illiquidity and Stock Returns: Cross-Section and Time-Series Effects, Journal of Financial Markets 5, 31-56.

Amihud, Y., and C. Hurvich (2004). Predictive Regressions: A Reduced-Bias Estimation Method, Journal of Financial and Quantitative Analysis 39, 813841.

Amihud, Y., C. Hurvich, and Y. Wang (2009). Multiple-Predictor Regressions: Hypothesis Testing, Review of Financial Studies 22, 413-434.

Andreu, E., E. Ghysels, and A. Kourtellos (2010). Should Macroeconomic Forecasters Use Daily Financial Data and How? Working Paper, University of North Carolina.

Ang, A., M. Piazzesi, and M. Wei (2006). What Does the Yield Curve Tell Us about GDP Growth? Journal of Econometrics 131, 359-403.

Backus, D., M. Chernov, and I. Martin (2011). Disasters Implied by Equity Index Options, Working Paper, New York University.

Bloom, N. (2009). The Impact of Uncertainty Shocks, Econometrica 77, 623-685.

Brennan, M., and A. Taylor (2010). Predicting the Market Using Information from Equity Portfolio Returns, Working Paper, Manchester University.

Campbell, J., and M. Yogo (2006). Efficient Tests of Stock Market Predictability, Journal of Financial Economics 81, 27-60. 
Campbell, J., M. Lettau, B. Malkiel, and Y. Xu (2001). Have Individual Stocks Become More Volatile? An Empirical Exploration of Idiosyncratic Risk, Journal of Finance 56, 1-43.

Cavanagh, C., G. Elliot, and J. Stock (1995). Inference in Models with Nearly Integrated Regressors, Econometric Theory 11, 1131-1147.

Chauvet, M., Z. Senyuz, and E. Yoldas (2011). What Does Realized Volatility Tell Us About Macroeconomic Fluctuations? Working Paper, University of California, Riverside.

Clark, T., and M. McCracken (2001). Tests of Equal Forecast Accuracy and Encompassing for Nested Models, Journal of Econometrics 105, 85-110.

Clark, T., and M. McCracken (2011). Reality Checks and Nested Forecast Model Comparisons, Forthcoming, Journal of Business and Economic Statistics.

Cochrane, J. (2008). The Dog That Did Not Bark: A Defense of Return Predictability, Review of Financial Studies 21, 1533-1575.

Cochrane, J. (2011). Discount Rates, Journal of Finance 66, 1047-1108.

Diebold, F., and R. Mariano (1995). Comparing Predictive Accuracy, Journal of Business Economics and Statistics 13, 253-263.

Elliot, G., and J. Stock (1994). Inference in Time Series Regression when the Order of Integration of a Regressor is Unknown, Econometric Theory 10, 672-700.

Estrella, A., and G. Hardouvelis (1991). The Term Structure as a Predictor of Real Economic Activity, Journal of Finance 46, 555-576.

Estrella, A., and F. Mishkin (1998). Predicting U.S. Recessions: Financial Variables as Leading Indicators, Review of Economics and Statistics 80, 45-61.

Fama, E. (1981). Stock Returns, Real Activity, Inflation, and Money, American Economic Review 71, 545-565. 
Fama, E. (1990). Stock Returns, Expected Returns, and Real Activity, Journal of Finance 45, 1089-1108.

Fama, E., and K. French (1993). Common Risk Factors in the Returns on Stocks and Bonds, Journal of Financial Economics 33, 3-56.

Ferreira, M., and P. Santa-Clara (2011). Forecasting Stock Market Returns: The Sum of the Parts Is More Than the Whole, Journal of Financial Economics 100, 514537.

Fornari, F., and A. Mele (2011). Financial Volatility and Economic Activity, Working Paper, London School of Economics.

Gilchrist, S., V. Zankov, and E. Zakrajsek (2009). Credit Market Shocks and Economic Fluctuations: Evidence from Corporate Bond and Stock Markets, NBER Working Paper No. 14863.

Goncalves, S., and L. Killian (2004). Bootstrapping Autoregressions with Conditional Heteroskedasticity of Unknown Form, Journal of Econometrics 123, 89-120.

Goyal, A., and P. Santa-Clara (2003). Idiosyncratic Risk Matters!, Journal of Finance $58,975-1007$.

Goyal, A., and I. Welch (2008). A Comprehensive Look at the Empirical Performance of Equity Premium Prediction, Review of Financial Studies 21, 1455-1508.

Hansen, L., and Jagannathan, R. (1991). Implications of Security Market Data for Models of Dynamic Economies, Journal of Political Economy 99, 225-262.

Hasbrouck, J. (2009). Trading Costs and Returns for US Equities: Estimating Effective Costs from Daily Data, Journal of Finance 64, 1445-1477.

Kiyotaki, N., and J. Moore (1997). Credit Cycles, Journal of Political Economy 105, 211-248. 
Lewellen, J. (2004). Predicting Returns with Financial Ratios, Journal of Financial Economics 74, 209-235.

McCracken, M. (2007). Asymptotics for Out-of-Sample Tests of Granger Causality, Journal of Econometrics 140, 719-752.

Mele, A. (2007). Asymmetric Stock Market Volatility and the Cyclical Behavior of Expected Returns, Journal of Financial Economics 86, 446-478.

Mele, A. (2008). Aggregate Stock Market Risk Premia and Real Economic Activity, Working Paper, London School of Economics.

Mueller, P. (2009). Credit Spreads and Real Activity. Working paper, London School of Economics.

Naes, R., J. Skjeltorp, and B. Arne-Odegaard (2011). Stock Market Liquidity and the Business Cycle, Journal of Finance 66, 139-176.

Newey, W., and K. West (1987). A Simple Positive Semi-definite, Heteroskedasticity and Autocorrelation Consistent Covariance Matrix, Econometrica 55, 703-708.

Nieto, B., and G. Rubio (2011). The Volatility of Consumption-Based Stochastic Discount Factors and Economic Cycles, Journal of Banking and Finance 35, 2197-2216.

Pastor, L., and P. Veronesi (2009). Technological Revolutions and Stock Prices, American Economic Review 99, 1451-1483.

Pérez-Quirós, G., and A. Timmermann (2000). Firm Size and Cyclical Variations in Stock Returns, Journal of Finance 55, 1229-1262.

Schwert, W. (1989). Business Cycles, Financial Crisis, and Stock Volatility, CarnegieRochester Conference Series on Public Policy 31, 83-126.

Schwert, W. (1990). Stock Returns and Real Activity: A Century of Evidence, Journal of Finance 45, 1237-1257. 
Stambaugh, R. (1999). Predictive Regressions, Journal of Financial Economics 5, 375421.

Stock, J. (1994). Unit Roots, Structural Breaks and Trends, Engle, R., McFadden, D. (Eds.), Handbook of Econometrics 4, Elsevier Science, New York, 2739-2841.

Stock, J., and M. Watson (2003). Forecasting Output and Inflation: The Role of Asset Prices, Journal of Economic Literature 41, 788-829.

Torous, W., R. Valkanov, and R. Yan (2004). On Predicting Stock Returns with Nearly Integrated Explanatory Variables, Journal of Business 77, 937-966.

West, K. (1996). Asymptotic Inference about Predictive Ability, Econometrica 64, $1067-1084$. 
Table 1

Descriptive statistics of the Hansen-Jagannathan volatility bound

\begin{tabular}{lc|lc}
\hline \multicolumn{2}{c|}{ Descriptive statistics } & \multicolumn{2}{c}{ Correlation between } \\
\hline Meannovations \\
Median & 0.504 & 1 month & -0.014 \\
Std. Dev. & 0.496 & 3 months & 0.060 \\
Skewness & 0.148 & 6 months & 0.040 \\
Kurtosis & 0.234 & 12 months & 0.008 \\
Autocorrelation & 3.378 & 24 months & 0.110 \\
\hline
\end{tabular}

On the left side, this table reports the descriptive statistics about the Hansen-Jagannathan volatility bound estimated with overlapping subperiods of five years of monthly data from size-sorted portfolios. Sample period goes from January 1927 to December 2010. On the right side of the table, we present the correlation between the residuals from the predictive regression and an $\mathrm{AR}(1)$ process for the predictor for each forecasting horizon. That is, $\operatorname{Corr}(\hat{\varepsilon}, \hat{u})$ from the model

$$
\begin{aligned}
& \Delta I P I_{t, t+1}=\alpha+\beta \sigma_{t}(M)+\varepsilon_{t+1} \\
& \sigma_{t+1}(M)=\alpha+\beta \sigma_{t}(M)+u_{t+1}
\end{aligned},
$$

where $\triangle I P I$ and $\sigma(M)$ denote the industrial production index growth and the Hansen-Jagannathan volatility bound respectively. 
Table 2

Forecasting power of the Hansen-Jagannathan volatility bound

\begin{tabular}{|c|c|c|c|c|c|c|c|}
\hline \multicolumn{8}{|c|}{ PANEL A: In sample forecasting ability } \\
\hline \multicolumn{4}{|c|}{$\Delta I P I_{t, t+\tau}=\alpha+\beta \sigma_{t}(M)+\varepsilon_{t+\tau}$} & \multicolumn{4}{|c|}{$\Delta I P I_{t, t+\tau}=\alpha+\beta_{1} \Delta I P I_{t-\tau, t}+\beta_{2} \sigma_{t}(M)+\varepsilon_{t+\tau}$} \\
\hline$\tau$ & $\alpha$ & $\beta$ & Adj. $R^{2}$ & $\alpha$ & $\beta_{1}$ & $\beta_{2}$ & $\operatorname{Adj.} R^{2}$ \\
\hline 1 & $\begin{array}{l}0.007 \\
(4.26)\end{array}$ & $\begin{array}{l}-0.009 \\
(-3.02)\end{array}$ & 3.24 & $\begin{array}{l}0.005 \\
(3.49)\end{array}$ & $\begin{array}{l}0.326 \\
(4.39)\end{array}$ & $\begin{array}{l}-0.006 \\
(-2.74)\end{array}$ & 13.37 \\
\hline 3 & $\begin{array}{l}0.021 \\
(4.89)\end{array}$ & $\begin{array}{l}-0.030 \\
(-3.42)\end{array}$ & 6.95 & $\begin{array}{l}0.013 \\
(3.85)\end{array}$ & $\begin{array}{l}0.424 \\
(5.57)\end{array}$ & $\begin{array}{l}-0.019 \\
(-3.11)\end{array}$ & 23.99 \\
\hline 6 & $\begin{array}{l}0.042 \\
(5.34)\end{array}$ & $\begin{array}{l}-0.060 \\
(-3.66)\end{array}$ & 9.41 & $\begin{array}{l}0.032 \\
(3.92)\end{array}$ & $\begin{array}{l}0.282 \\
(2.88)\end{array}$ & $\begin{array}{l}-0.047 \\
(-3.11)\end{array}$ & 16.72 \\
\hline 12 & $\begin{array}{l}0.080 \\
(5.91)\end{array}$ & $\begin{array}{l}-0.111 \\
(-3.95)\end{array}$ & 12.36 & $\begin{array}{l}0.077 \\
(5.41)\end{array}$ & $\begin{array}{l}-0.003 \\
(-0.03)\end{array}$ & $\begin{array}{l}-0.107 \\
(-2.48)\end{array}$ & 11.80 \\
\hline 24 & $\begin{array}{c}0.149 \\
(7.16)\end{array}$ & $\begin{array}{l}-0.207 \\
(-4.74)\end{array}$ & 19.56 & $\begin{array}{l}0.157 \\
(7.99)\end{array}$ & $\begin{array}{l}-0.299 \\
(-2.98)\end{array}$ & $\begin{array}{l}-0.193 \\
(-4.45)\end{array}$ & 25.92 \\
\hline
\end{tabular}

PANEL B: Other proxies for economic growth

\begin{tabular}{c|ccc|ccc}
\hline \multicolumn{2}{c}{$\Delta G D P_{t, t+\tau}=\alpha+\beta \sigma_{t}(M)+\varepsilon_{t+\tau}$} & \multicolumn{3}{c}{$\Delta c_{t, t+\tau}=\alpha+\beta \sigma_{t}(M)+\varepsilon_{t+\tau}$} \\
\hline$\tau$ & $\alpha$ & $\beta$ & $A d j . R^{2}$ & $\alpha$ & $\beta$ & $A d j . R^{2}$ \\
\hline \multirow{2}{*}{1} & 0.005 & -0.005 & 0.86 & 0.004 & -0.004 & 3.42 \\
& $(3.53)$ & $(-1.85)$ & & $(7.87)$ & $(-4.67)$ & \\
3 & 0.015 & -0.013 & 5.10 & 0.012 & -0.014 & 12.51 \\
& $(3.71)$ & $(-1.88)$ & & $(8.52)$ & $(-5.01)$ & \\
6 & 0.027 & -0.024 & 7.43 & 0.023 & -0.025 & 16.84 \\
& $(4.03)$ & $(-1.90)$ & & $(8.98)$ & $(-5.10)$ & \\
12 & 0.058 & -0.054 & 13.64 & 0.045 & -0.049 & 21.63 \\
& $(5.33)$ & $(-2.64)$ & & $(10.38)$ & $(-5.70)$ & 27.08 \\
& 0.132 & -0.134 & 32.26 & 0.088 & -0.091 & $(-6.38)$ \\
\hline
\end{tabular}

PANEL C: Different sample periods

\begin{tabular}{c|ccc|ccc|ccc}
\hline \multicolumn{7}{c}{$\Delta I P I_{t, t+\tau}=\alpha+\beta \sigma_{t}(M)+\varepsilon_{t+\tau}$} \\
\hline \multicolumn{3}{c}{$1965: 1987$} & \multicolumn{3}{c}{$1988: 2010$} & \multicolumn{3}{c}{$1931: 2010$} \\
\hline \multirow{2}{*}{1} & $\alpha$ & $\beta$ & $A d j . R^{2}$ & $\alpha$ & $\beta$ & $A d j . R^{2}$ & $\alpha$ & $\beta$ & Adj. $R^{2}$ \\
& 0.009 & -0.014 & 3.22 & 0.007 & -0.009 & 3.11 & 0.010 & -0.015 & 1.11 \\
& $(4.40)$ & $(-3.06)$ & & $(2.90)$ & $(-2.02)$ & & $(2.64)$ & $(-2.05)$ & \\
& 0.029 & -0.050 & 8.08 & 0.020 & -0.026 & 6.85 & 0.028 & -0.039 & 1.47 \\
& $(5.46)$ & $(-3.65)$ & & $(2.99)$ & $(-2.06)$ & & $(2.75)$ & $(-2.06)$ & \\
& 0.062 & -0.112 & 14.31 & 0.037 & -0.046 & 6.72 & 0.053 & -0.069 & 2.03 \\
& $(6.40)$ & $(-4.36)$ & & $(2.96)$ & $(-1.95)$ & & $(3.15)$ & $(-2.26)$ & \\
12 & 0.122 & -0.223 & 22.87 & 0.065 & -0.078 & \multirow{2}{*}{6.77} & 0.110 & -0.145 & 4.13 \\
& $(7.53)$ & $(-5.51)$ & & $(3.13)$ & $(-1.94)$ & & $(4.45)$ & $(-3.27)$ & \\
24 & 0.200 & -0.352 & 30.00 & 0.148 & -0.188 & 16.29 & 0.227 & -0.310 & 10.61 \\
& $(8.95)$ & $(-6.74)$ & & $(4.34)$ & $(-2.88)$ & & $(6.40)$ & $(-4.82)$ & \\
\hline
\end{tabular}

PANEL D: Out of sample forecasting ability

Unrestricted: $\Delta I P I_{t, t+\tau}=\alpha+\beta \sigma_{t}(M)+\varepsilon_{t+\tau} \quad$ Unrestricted:

Restricted: $\Delta I P I_{t, t+\tau}=\alpha+\varepsilon_{t+\tau}$

\begin{tabular}{c|ccc|ccc}
\hline$\tau$ & $R M S E$ & $M S E-t$ & $M S E-F$ & $R M S E$ & MSE- $t$ & $M S E-F$ \\
\hline \multirow{2}{*}{1} & 0.9708 & 1.557 & 14.667 & 0.9907 & 0.827 & 4.383 \\
& & $(0.0004)$ & $(0.0002)$ & & $(0.012)$ & $(0.016)$ \\
3 & 0.9431 & 1.280 & 29.346 & 0.9762 & 0.620 & 11.296 \\
& & $(0.0006)$ & $(0.0008)$ & & $(0.002)$ & $(0.004)$ \\
6 & 0.9299 & 1.007 & 34.418 & 0.9565 & 0.536 & 20.933 \\
& & $(0.001)$ & $(0.001)$ & & $(0.001)$ & $(0.002)$ \\
12 & 0.9437 & 0.492 & 28.453 & 0.9869 & 0.095 & 6.026 \\
& & $(0.0004)$ & $(0.0008)$ & & $(0.003)$ & $(0.003)$ \\
24 & 1.0051 & -0.025 & -2.343 & 1.0081 & -0.037 & -3.532 \\
& & $(0.001)$ & $(0.001)$ & & $(0.005)$ & $(0.005)$ \\
\hline
\end{tabular}


In Panel A, this table reports the results from monthly forecasting regressions of the industrial production growth, $\triangle I P I$, on the Hansen-Jagannathan $(\mathrm{HJ})$ volatility bound, $\sigma(M)$, estimated with overlapping sub-periods of 60 months of returns from size-sorted portfolios. Forecasting horizons, $\tau=$ $1,3,6,12$, and 24 months, are indicated in the first column. Numbers in parentheses are $t$-values based on OLS autocorrelation-robust standard errors. Sample period goes from January 1965 to July 2010.

In Panel B, the forecasting ability of the $\mathrm{HJ}$ volatility bound is confirmed when using two alternative proxies for macroeconomic growth: the gross domestic product growth, $\triangle G D P$, on the left side, and non-durable consumption growth, $\Delta c$, on the right side, respectively.

In Panel $\mathrm{C}$, the forecasting ability of the $\mathrm{HJ}$ volatility bound is confirmed when using alternative sample periods: two sub-periods, from January 1965 to December 1987 and from January 1988 to July 2010, and also an extended period, from January 1931 to July 2010, that uses all IPI available data.

Finally, Panel D shows the out-of-sample forecast accuracy of the HJ volatility bound, compared with a constant specification, on the left side, and with an $\operatorname{AR}(1)$ specification, on the right side, respectively. RMSE is the relative mean square forecasting error that compares the mean square forecasting error of the restricted model and the mean square error of the unrestricted model. MSE- $t$ and $M S E-F$ are two statistics for testing the equal forecasting ability of the two models, restricted and unrestricted. $P$-values, in parentheses, are obtained by an efficient bootstrap method for simulating asymptotic critical values. Sample period goes from January 1965 to July 2010. 
Table 3.a

Forecasting power of the Hansen-Jagannathan bound against alternative standard predictors Forecasting horizon: 1 month

\begin{tabular}{|c|c|c|c|c|}
\hline \multicolumn{5}{|c|}{$\begin{array}{c}\text { PANEL A: In sample forecasting ability } \\
\Delta I P I_{t, t+\tau}=\alpha+\beta_{1} \sigma_{t}(M)+\beta_{2} X_{t}+\varepsilon_{t+\tau}, \tau=1\end{array}$} \\
\hline$X$ & $\alpha$ & $\beta_{1}$ & $\beta_{2}$ & $\operatorname{Adj} . R^{2}$ \\
\hline \multirow{4}{*}{ Market Return } & 0.002 & & 0.004 & 0.00 \\
\hline & $(4.11)$ & & $(0.45)$ & \\
\hline & 0.007 & -0.009 & 0.003 & 3.09 \\
\hline & $(4.37)$ & $(-3.06)$ & $(0.35)$ & \\
\hline \multirow{4}{*}{ Price/Dividend } & 0.005 & & -0.960 & 1.37 \\
\hline & $(3.29)$ & & $(-1.64)$ & \\
\hline & 0.014 & -0.015 & -1.903 & 8.08 \\
\hline & $(5.20)$ & $(-4.43)$ & $(-3.02)$ & \\
\hline \multirow{4}{*}{ Default Premium } & 0.007 & & -3.344 & 7.28 \\
\hline & $(6.02)$ & & $(-3.97)$ & \\
\hline & 0.012 & -0.008 & -3.100 & 9.38 \\
\hline & $(8.86)$ & $(-3.18)$ & $(-3.96)$ & \\
\hline \multirow{4}{*}{ Term Spread } & 0.001 & & 1.050 & 2.55 \\
\hline & $(1.28)$ & & $(2.92)$ & \\
\hline & 0.005 & -0.008 & 0.788 & 4.49 \\
\hline & $(2.24)$ & $(-2.05)$ & $(1.83)$ & \\
\hline \multirow{4}{*}{ Market Illiquidity } & 0.002 & & -0.0005 & 0.27 \\
\hline & $(4.15)$ & & $(-1.77)$ & \\
\hline & 0.006 & -0.008 & -0.0005 & 2.84 \\
\hline & $(4.12)$ & $(-2.89)$ & $(-1.46)$ & \\
\hline
\end{tabular}

PABEL B: Out-of-sample forecasting ability

Unrestricted model: $\Delta I P I_{t, t+\tau}=\alpha+\beta_{1} \mathrm{X}_{\mathrm{t}}+\beta_{2} \sigma_{t}(M)+\varepsilon_{t+\tau}, \tau=1$

Restricted model: $\Delta I P I_{t, t+\tau}=\alpha+\beta_{1} \mathrm{X}_{\mathrm{t}}+\varepsilon_{t+\tau}, \tau=1$

\begin{tabular}{lccccc}
\hline & Market Return & Price/Dividend & $\begin{array}{c}\text { Default } \\
\text { Premium }\end{array}$ & Term Spread & $\begin{array}{c}\text { Market } \\
\text { Illiquidity }\end{array}$ \\
\hline$R M S E$ & 0.9709 & 0.9389 & 0.9886 & 0.9869 & 0.9389 \\
$M S E-t$ & 1.5537 & 1.9240 & 0.4114 & 1.0460 & 1.2061 \\
$(p$-value $)$ & $(0)$ & $(0)$ & $(0)$ & $(0.099)$ & $(0.003)$ \\
$M S E-F$ & 14.6251 & 31.7330 & 5.6467 & 6.4758 & 30.4443 \\
$(p$-value $)$ & $(0)$ & $(0)$ & $(0)$ & $(0.075)$ & $(0.007)$ \\
\hline
\end{tabular}

Panel A: Monthly forecasting regressions of the industrial production growth, $\triangle I P I$, on the HansenJagannathan $(\mathrm{HJ})$ volatility bound, $\sigma(M)$, estimated with overlapping sub-periods of 60 months of returns from 10 size-sorted portfolios and/or an additional standard predictor, indicated in column 1 . The default premium is calculated as the spread between the rates of Baa corporate bonds and 10-year government bonds. The term spread is measured as the difference between the 10 -year government bond and the onemonth T-bill rate. The market-wide illiquidity measure is calculated from Amihud's (2002) ratio. Numbers in parentheses are $t$-values based on OLS autocorrelation-robust standard errors. Sample period goes from January 1965 to July 2010.

Panel B: The out-of-sample forecast accuracy of the HJ volatility bound is analyzed, comparing the unrestricted model that contains the HJ bound and the additional standard predictor, with the restricted model, that only includes the HJ bound as the predictor. RMSE is the relative mean square forecasting error that compares the mean square forecasting error of the restricted model and the mean square error of the unrestricted model. $M S E-t$ and $M S E-F$ are two statistics for testing the equal forecasting ability of the two models, restricted and unrestricted. $P$-values, in parentheses, are obtained by an efficient bootstrap method for simulating asymptotic critical values. Sample period goes from January 1965 to July 2010. Each table from 3.a to 3.e refers to a different forecasting horizon. 
Table 3.b

Forecasting power of the Hansen-Jagannathan bound against alternative standard predictors Forecasting horizon: 3 months

\begin{tabular}{|c|c|c|c|c|c|}
\hline \multicolumn{6}{|c|}{ PANEL A: In sample forecasting ability } \\
\hline$X$ & & $\alpha$ & $\beta_{1}$ & $\beta_{2}$ & $\operatorname{Adj} . R^{2}$ \\
\hline \multirow{4}{*}{ Market Return } & \multicolumn{2}{|c|}{0.006} & & 0.059 & \multirow[t]{2}{*}{2.46} \\
\hline & \multicolumn{2}{|c|}{$(3.82)$} & & $(2.62)$ & \\
\hline & & & -0.030 & 0.056 & \multirow[t]{2}{*}{9.16} \\
\hline & \multicolumn{2}{|c|}{$(5.01)$} & $(-3.58)$ & $(2.84)$ & \\
\hline \multirow{4}{*}{ Price/Dividend } & \multirow{2}{*}{\multicolumn{2}{|c|}{$\begin{array}{l}0.013 \\
(3.21)\end{array}$}} & & -2.659 & \multirow[t]{2}{*}{2.21} \\
\hline & & & & $(-1.57)$ & \\
\hline & \multirow{2}{*}{\multicolumn{2}{|c|}{$\begin{array}{l}0.043 \\
(5.37)\end{array}$}} & -0.046 & -5.605 & \multirow[t]{2}{*}{15.53} \\
\hline & & & $(-4.72)$ & $(-3.04)$ & \\
\hline \multirow{4}{*}{ Default Premium } & \multicolumn{2}{|c|}{0.018} & & -7.410 & \multirow[t]{2}{*}{7.16} \\
\hline & \multicolumn{2}{|c|}{$(4.60)$} & & $(-2.81)$ & \\
\hline & & & -0.027 & -6.566 & \multirow[t]{2}{*}{12.45} \\
\hline & \multicolumn{2}{|c|}{$(5.78)$} & $(-3.73)$ & $(-2.77)$ & \\
\hline \multirow{4}{*}{ Term Spread } & \multicolumn{2}{|c|}{0.002} & & 3.599 & \multirow[t]{2}{*}{6.25} \\
\hline & \multirow{2}{*}{\multicolumn{3}{|c|}{$\begin{array}{l}(1.06) \\
0.015\end{array}$}} & $(3.66)$ & \\
\hline & & 015 & & 2.769 & \multirow{2}{*}{10.31} \\
\hline & \multicolumn{2}{|c|}{$(2.43)$} & $(-2.26)$ & $(2.34)$ & \\
\hline \multirow{4}{*}{ Market Illiquidity } & \multirow{4}{*}{\multicolumn{2}{|c|}{$\begin{array}{l}0.006 \\
(4.18) \\
0.020 \\
(4.80)\end{array}$}} & & -0.001 & \multirow[t]{2}{*}{0.38} \\
\hline & & & & $(-2.88)$ & \\
\hline & & & -0.029 & -0.001 & \multirow[t]{2}{*}{6.66} \\
\hline & & & $(-3.35)$ & $(-2.53)$ & \\
\hline \multirow{3}{*}{\multicolumn{6}{|c|}{$\begin{array}{c}\text { PABEL B: Out-of-sample forecasting ability } \\
\text { Unrestricted model: } \Delta I P I_{t, t+\tau}=\alpha+\beta_{1} \mathrm{X}_{\mathrm{t}}+\beta_{2} \sigma_{t}(M)+\varepsilon_{t+\tau}, \tau=3 \\
\text { Restricted model: } \Delta I P I_{t, t+\tau}=\alpha+\beta_{1} \mathrm{X}_{\mathrm{t}}+\varepsilon_{t+\tau}, \tau=3\end{array}$}} \\
\hline & & & & & \\
\hline & & & & & \\
\hline & Market Return & Price/Dividend & $\begin{array}{c}\text { Default } \\
\text { Premium }\end{array}$ & Term Spread & $\begin{array}{l}\text { Market } \\
\text { Illiquidity }\end{array}$ \\
\hline RMSE & 0.9431 & 0.8967 & 0.9789 & 0.9770 & 0.9243 \\
\hline$M S E-t$ & 1.2967 & 1.3724 & 0.3810 & 0.8389 & 1.2601 \\
\hline ( $p$-value) & (0) & (0) & (0) & $(0.234)$ & (0) \\
\hline$M S E-F$ & 29.3053 & 55.9710 & 10.4856 & 11.4637 & 38.1428 \\
\hline ( $p$-value) & $(0)$ & (0) & $(0)$ & $(0.215)$ & $(0.003)$ \\
\hline
\end{tabular}

See notes in Table 3.a. 
Table 3.c

Forecasting power of the Hansen-Jagannathan bound against alternative standard predictors Forecasting horizon: 6 months

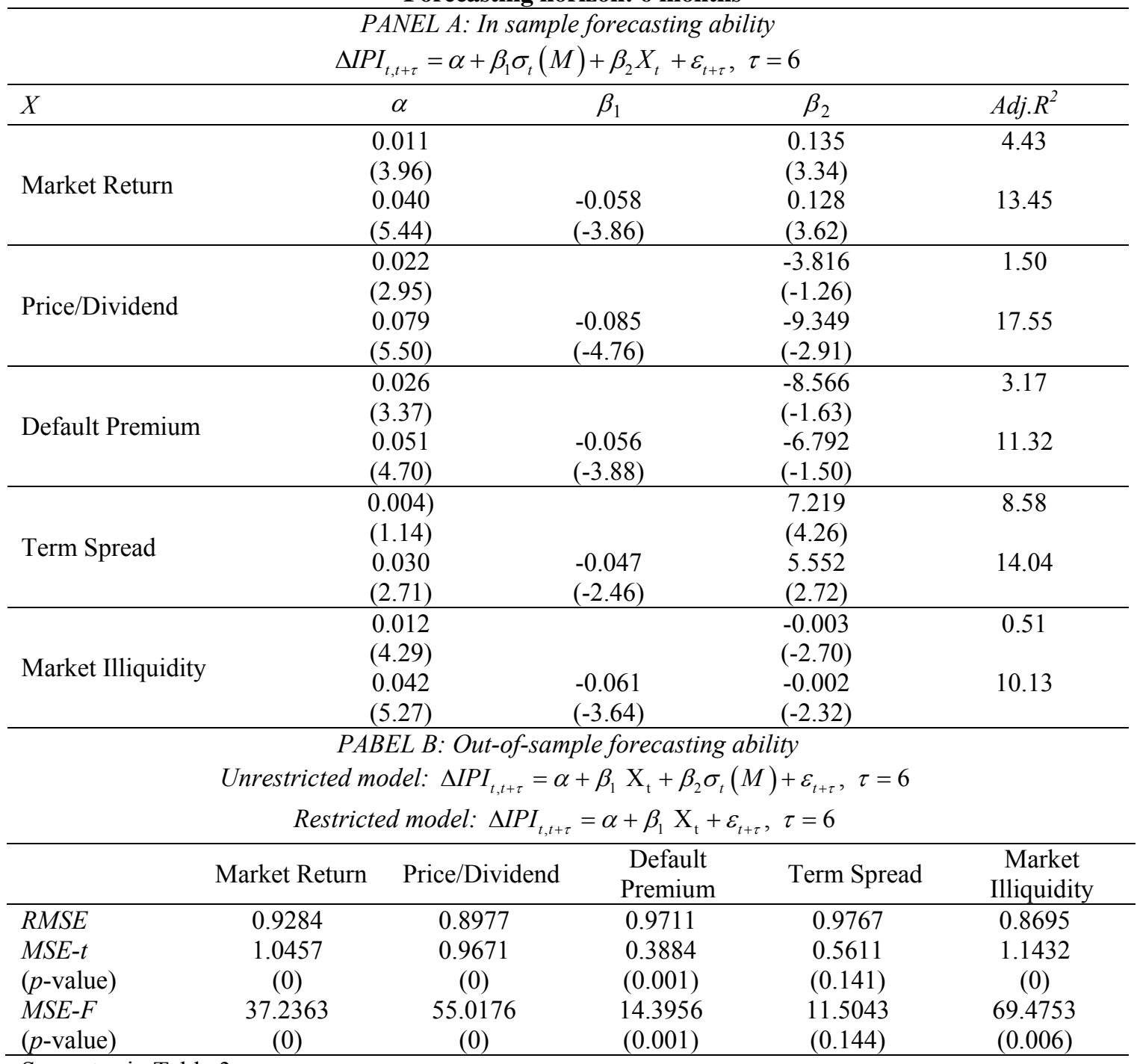

See notes in Table 3.a. 
Table 3.d

Forecasting power of the Hansen-Jagannathan bound against alternative standard predictors Forecasting horizon: 12 months

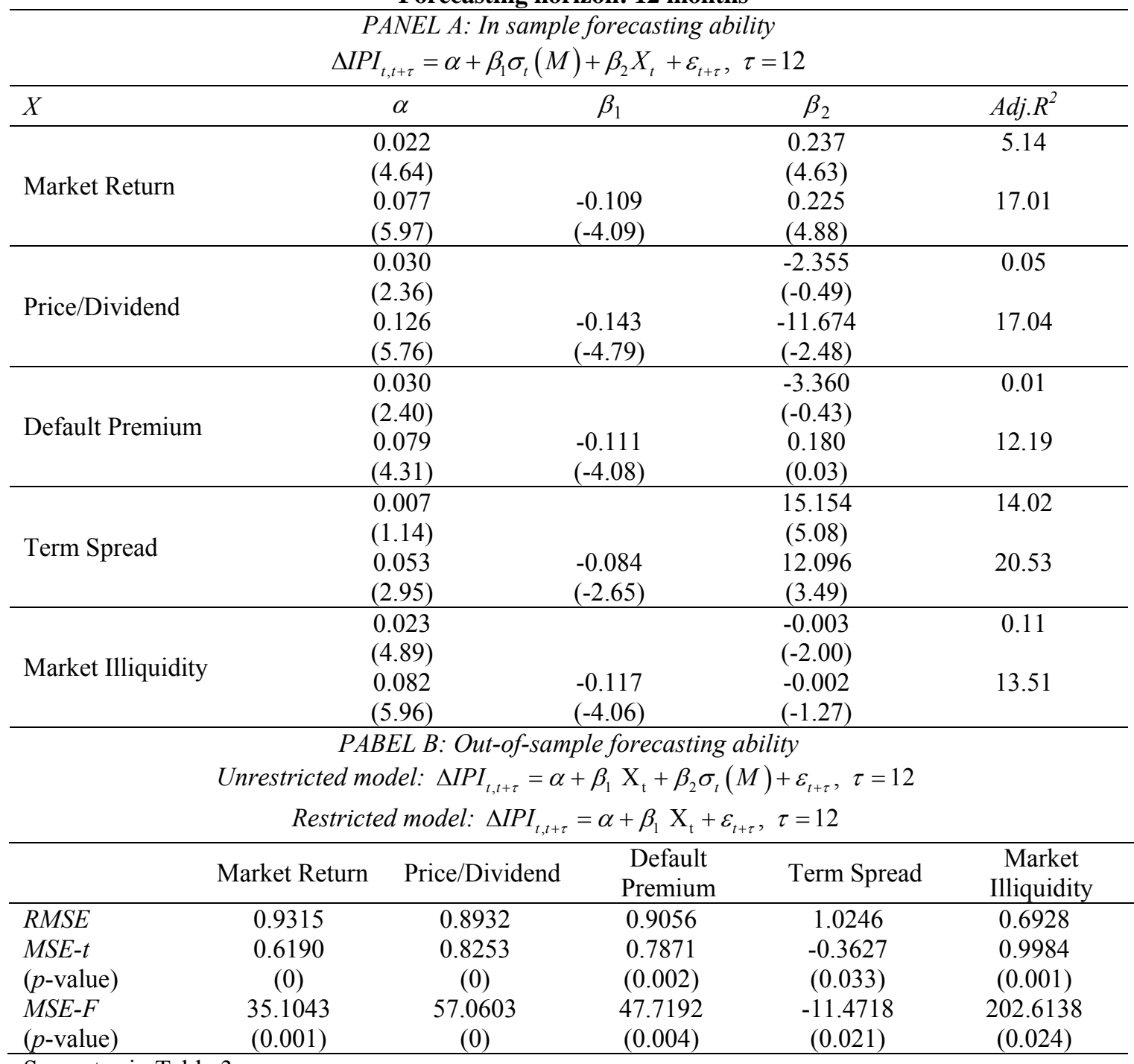

See notes in Table 3.a. 
Table 3.e

Forecasting power of the Hansen-Jagannathan bound against alternative standard predictors Forecasting horizon: 24 months

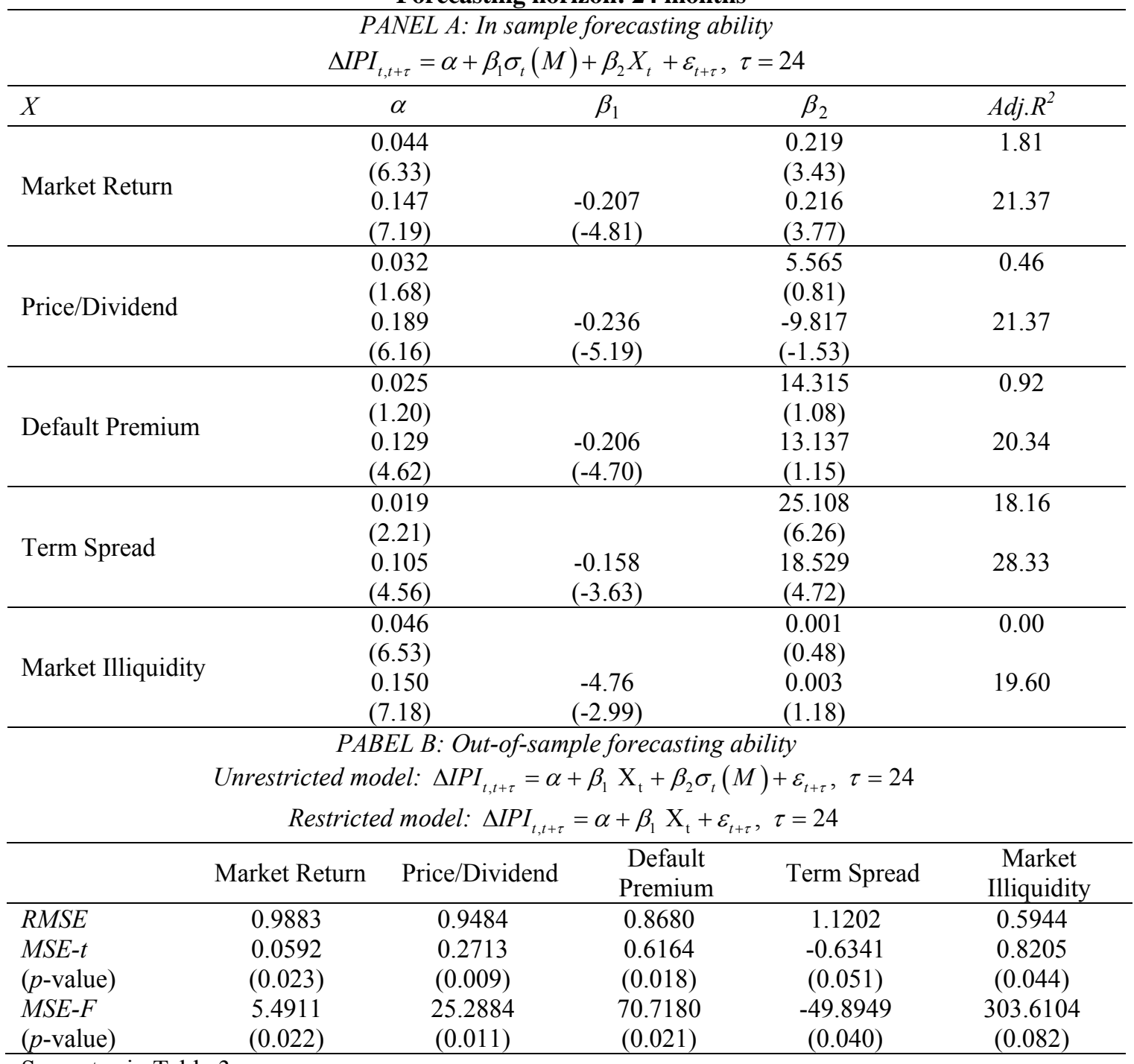

See notes in Table 3.a. 
Table 4

Forecasting power of the Hansen-Jagannathan bound against alternative uncertainty measures

\begin{tabular}{|c|c|c|c|c|}
\hline \multicolumn{5}{|c|}{$\Delta I P I_{t, t+\tau}=\alpha+\beta_{1} \sigma_{t}(M)+\beta_{2} X_{t}+\varepsilon_{t+\tau}, \tau=3$} \\
\hline \multicolumn{5}{|c|}{ Idiosyncratic Risk. Simple period: 1965:01-2010:07 } \\
\hline & $\alpha$ & $\beta_{1}$ & $\beta_{2}$ & $\operatorname{Adj} . R^{2}$ \\
\hline \multirow{3}{*}{ Daily Data } & $\begin{array}{l}0.009 \\
(6.29)\end{array}$ & & -0.981 & 8.81 \\
\hline & 0.024 & -0.029 & -0.904 & 14.95 \\
\hline & $(6.05)$ & $(-3.68)$ & $(-3.00)$ & \\
\hline \multirow{4}{*}{ Monthly Data } & 0.007 & & -0.387 & 0.49 \\
\hline & $(4.32)$ & & $(-1.26)$ & \\
\hline & 0.023 & -0.032 & -0.413 & 8.14 \\
\hline & $(4.82)$ & $(-3.43)$ & $(-1.33)$ & \\
\hline \multicolumn{5}{|c|}{ Volatility of SMB Factor. Sample period: 1965:01-2010:07 } \\
\hline & $\alpha$ & $\beta_{1}$ & $\beta_{2}$ & Adj. $R^{2}$ \\
\hline \multirow{4}{*}{ Daily Data } & 0.015 & & -0.455 & 8.49 \\
\hline & $(4.53)$ & & $(-2.49)$ & \\
\hline & 0.027 & -0.026 & -0.381 & 13.17 \\
\hline & $(5.62)$ & $(-3.13)$ & $(-2.43)$ & \\
\hline \multirow{4}{*}{ Monthly Data } & 0.010 & & -0.134 & 0.40 \\
\hline & $(2.42)$ & & $(-1.07)$ & \\
\hline & 0.033 & -0.036 & -0.266 & 9.53 \\
\hline & $(5.77)$ & $(-3.73$ & $(-2.53)$ & \\
\hline \multicolumn{5}{|c|}{ Volatility of Market Return. Sample period: 1965:01-2010:07 } \\
\hline & $\alpha$ & $\beta_{1}$ & $\beta_{2}$ & $\operatorname{Adj.} R^{2}$ \\
\hline \multirow{4}{*}{ Fornari-Mele } & 0.014 & & -0.180 & 2.61 \\
\hline & $(3.66)$ & & $(-1.86)$ & \\
\hline & 0.033 & -0.034 & -0.210 & 11.17 \\
\hline & $(5.08)$ & $(-3.70)$ & $(-2.19)$ & \\
\hline \multirow{4}{*}{5 years of monthly data } & 0.013 & & -0.148 & 0.35 \\
\hline & $(1.74)$ & & $(-0.90)$ & \\
\hline & 0.047 & -0.041 & -0.461 & 11.01 \\
\hline & $(5.27)$ & $(-4.20)$ & $(-3.17)$ & \\
\hline \multicolumn{5}{|c|}{ VIX. Sample period: 1986:01-2010:07 } \\
\hline & $\alpha$ & $\beta_{1}$ & $\beta_{2}$ & $\operatorname{Adj.} R^{2}$ \\
\hline \multirow{4}{*}{ Last day of each month } & 0.019 & & -0.065 & 13.57 \\
\hline & $(3.75)$ & & $(-2.33)$ & \\
\hline & 0.041 & -0.036 & -0.072 & 25.62 \\
\hline & $(4.38)$ & $(-3.06)$ & $(-3.33)$ & \\
\hline \multicolumn{5}{|c|}{ Dispersion in SPF. Quarterly Data. Sample period: 1968:IV-2010:4 } \\
\hline & $\alpha$ & $\beta_{1}$ & $\beta_{2}$ & $\operatorname{Adj} . R^{2}$ \\
\hline \multirow{4}{*}{$D 2$ for $G D P$ growth } & 0.009 & & -0.002 & 0.15 \\
\hline & $(2.36)$ & & $(-0.91)$ & \\
\hline & 0.036 & -0.042 & -0.005 & 12.15 \\
\hline & $(4.40)$ & $(-3.34)$ & $(-2.27)$ & \\
\hline \multirow{4}{*}{$D 3$ for $G D P$ levels } & 0.011 & & -0.012 & 1.16 \\
\hline & $(2.62)$ & & $(-1.30)$ & \\
\hline & 0.038 & -0.043 & -0.024 & 14.10 \\
\hline & $(4.75)$ & $(-3.53)$ & $(-2.66)$ & \\
\hline
\end{tabular}

This table displays the results from predictive regressions using the HJ volatility bound, estimated with 10 size-sorted portfolios, and an alternative measure of uncertainty. Idiosyncratic risk is computed from 100 size-book-to-market value-weighted portfolios. Both idiosyncratic risk and the volatility of $S M B$ are estimated with a rolling window of one month of daily data, in the first row, and 60 months of monthly data, in the second row. The volatility of the market return is computed as in Fornari and Mele (2011), and also as the standard deviation of the monthly returns using a rolling window of 60 months. VIX refers to the last day of the corresponding month. $S P F$ indicates the prediction of GDP provided by the 
Survey of Professional Forecasters and $D_{2}$ and $D_{3}$ are two alternative cross-sectional dispersion measures. Numbers in parentheses are $t$-values based on OLS autocorrelation-robust standard errors. The sample period is indicated at the top of each block (due to data availability restrictions). Frequency is monthly for all regressions with the exception of the one that includes the SPF that is quarterly frequency. Each panel from A to D refers to a different forecasting horizon. 
Table 4 (continuation)

PANEL B: $\tau=6$ months

$\Delta I P I_{t, t+\tau}=\alpha+\beta_{1} \sigma_{t}(M)+\beta_{2} X_{t}+\varepsilon_{t+\tau}, \tau=6$

Idiosyncratic Risk. Sample period: 1965:01-2010:07

\begin{tabular}{lcccc}
\hline & $\alpha$ & $\beta_{1}$ & $\beta_{2}$ & $\operatorname{Adj}^{2}$ \\
\hline \multirow{3}{*}{ Daily Data } & 0.018 & & -1.572 & 7.59 \\
& $(6.21)$ & & $(-2.72)$ & \\
& 0.047 & -0.060 & -1.414 & 16.24 \\
Monthly Data & $(6.22)$ & $(-3.80)$ & $(-2.94)$ & 0.09 \\
& 0.013 & & -0.423 & \\
& $(4.23)$ & & $(-0.86)$ & 10.34 \\
\hline
\end{tabular}

Volatility of SMB Factor. Sample period: 1965:01-2010:07

\begin{tabular}{|c|c|c|c|c|}
\hline & $\alpha$ & $\beta_{1}$ & $\beta_{2}$ & Adj. $R^{2}$ \\
\hline \multirow{4}{*}{ Daily Data } & 0.027 & & -0.718 & 7.08 \\
\hline & $(4.60)$ & & $(-2.39)$ & \\
\hline & 0.052 & -0.055 & -0.560 & 14.21 \\
\hline & $(5.84)$ & $(-3.45)$ & $(-2.31)$ & \\
\hline \multirow{4}{*}{ Monthly Data } & 0.021 & & -0.273 & 0.63 \\
\hline & $(2.56)$ & & $(-1.15)$ & \\
\hline & 0.065 & -0.072 & -0.530 & 12.91 \\
\hline & $(6.06)$ & $(-3.96)$ & $(-2.67)$ & \\
\hline \multicolumn{5}{|c|}{ Volatility of Market Return. Sample period: 1965:01-2010:07 } \\
\hline & $\alpha$ & $\beta_{1}$ & $\beta_{2}$ & Adj. $R^{2}$ \\
\hline \multirow{4}{*}{ Fornari-Mele } & 0.021 & & -0.186 & 0.82 \\
\hline & $(2.98)$ & & $(-1.15)$ & \\
\hline & 0.057 & -0.067 & -0.242 & 11.76 \\
\hline & $(4.90)$ & $(-3.75)$ & $(-1.51)$ & \\
\hline \multirow{4}{*}{5 years of monthly data } & 0.018 & & -0.127 & 0.00 \\
\hline & $(1.19)$ & & $(-0.39)$ & \\
\hline & 0.082 & -0.076 & -0.715 & 12.72 \\
\hline & $(4.97)$ & $(-4.28)$ & $(-2.60)$ & \\
\hline \multicolumn{5}{|c|}{ VIX. Sample period: 1986:01-2010:07 } \\
\hline & $\alpha$ & $\beta_{1}$ & $\beta_{2}$ & $\operatorname{Adj} \cdot R^{2}$ \\
\hline \multirow{4}{*}{ Last day of each month } & 0.031 & & -0.098 & 9.61 \\
\hline & (3.99) & & $(-2.23)$ & \\
\hline & 0.070 & -0.064 & -0.110 & 21.35 \\
\hline & $(3.97)$ & $(-2.65)$ & $(-3.07)$ & \\
\hline \multicolumn{5}{|c|}{ Dispersion in SPF. Quarterly Data. Sample period: 1968:IV-2010:4 } \\
\hline & $\alpha$ & $\beta_{1}$ & $\beta_{2}$ & Adj. $R^{2}$ \\
\hline \multirow{4}{*}{$D 2$ for $G D P$ growth } & 0.013 & & -0.002 & -0.43 \\
\hline & $(1.88)$ & & $(-0.38)$ & \\
\hline & 0.063 & -0.078 & -0.007 & 13.46 \\
\hline & $(4.17)$ & $(-3.22)$ & $(-1.68)$ & \\
\hline \multirow{4}{*}{$D 3$ for $G D P$ levels } & 0.015 & & -0.012 & -0.09 \\
\hline & $(2.24)$ & & $(-0.70)$ & \\
\hline & 0.065 & -0.079 & -0.033 & 14.44 \\
\hline & $(4.51)$ & $(-3.34)$ & $(-2.06)$ & \\
\hline
\end{tabular}

See notes in Panel A 
Table 4 (continuation)

PANEL C: $\tau=12$ months

$\Delta I P I_{t, t+\tau}=\alpha+\beta_{1} \sigma_{t}(M)+\beta_{2} X_{t}+\varepsilon_{t+\tau}, \tau=12$

Idiosyncratic Risk. Sample period: 1965:01-2010:07

\begin{tabular}{lcccc}
\hline & $\alpha$ & $\beta_{1}$ & $\beta_{2}$ & Adj. $^{2}$ \\
\hline \multirow{3}{*}{ Daily Data } & 0.031 & & -1.837 & 3.65 \\
& $(6.17)$ & & $(-2.85)$ & \\
& 0.089 & -0.118 & -1.513 & 16.21 \\
Monthly Data & $(6.32)$ & $(-3.93)$ & $(-2.89)$ & -0.06 \\
& 0.026 & & -0.480 & 13.81 \\
& $(4.97)$ & & $(-0.74)$ & \\
\hline
\end{tabular}

Volatility of SMB Factor. Sample period: 1965:01-2010:07

\begin{tabular}{lcccc}
\hline & $\alpha$ & $\beta_{1}$ & $\beta_{2}$ & Adj. $R^{2}$ \\
\hline \multirow{3}{*}{ Daily Data } & 0.044 & & -0.956 & 4.53 \\
& $(5.15)$ & $-2.66)$ & \\
& 0.094 & -0.113 & -0.622 & 15.53 \\
Monthly Data & $(6.46)$ & $(-3.69)$ & $(-2.40)$ & 1.01 \\
& 0.041 & & -0.543 & 17.50 \\
\hline
\end{tabular}

\begin{tabular}{|c|c|c|c|c|}
\hline \multicolumn{5}{|c|}{ Volatility of Market Return. Sample period: 1965:01-2010:07 } \\
\hline & $\alpha$ & $\beta_{1}$ & $\beta_{2}$ & Adj. $R^{2}$ \\
\hline \multirow{4}{*}{ Fornari-Mele } & 0.030 & & -0.125 & -0.03 \\
\hline & $(2.39)$ & & $(-0.48)$ & \\
\hline & 0.098 & -0.126 & -0.228 & 14.26 \\
\hline & $(5.20)$ & $(-4.03)$ & $(-0.90)$ & \\
\hline \multirow{4}{*}{ Monthly Data } & 0.024 & & 0.001 & 0.00 \\
\hline & $(0.82)$ & & $(0.00)$ & \\
\hline & 0.138 & -0.136 & -1.051 & 15.00 \\
\hline & $(4.82)$ & $(-4.55)$ & $(-2.08)$ & \\
\hline \multicolumn{5}{|c|}{ VIX. Sample period: 1986:01-2010:07 } \\
\hline & $\alpha$ & $\beta_{1}$ & $\beta_{2}$ & $\operatorname{Adj} . R^{2}$ \\
\hline \multirow{4}{*}{ Last day of each month } & 0.045 & & -0.118 & 4.46 \\
\hline & $(5.26)$ & & $(-2.54)$ & \\
\hline & 0.111 & -0.109 & -0.138 & 15.82 \\
\hline & $(3.74)$ & $(-2.34)$ & $(-2.84)$ & \\
\hline \multicolumn{5}{|c|}{ Dispersion in SPF. Quarterly Data. Sample period: 1968:IV-2010:4 } \\
\hline & $\alpha$ & $\beta_{1}$ & $\beta_{2}$ & Adj. $R^{2}$ \\
\hline \multirow{4}{*}{$D 2$ for $G D P$ growth } & 0.020 & & 0.000 & -0.61 \\
\hline & $(1.65)$ & & $(0.06)$ & \\
\hline & 0.107 & -0.138 & -0.009 & 15.44 \\
\hline & $(4.24)$ & $(-3.18)$ & $(-1.45)$ & \\
\hline \multirow{4}{*}{$D 3$ for $G D P$ levels } & 0.025 & & -0.011 & -0.45 \\
\hline & $(2.08)$ & & $(-0.38)$ & \\
\hline & 0.115 & -0.142 & -0.050 & 16.80 \\
\hline & $(4.61)$ & $(-3.33)$ & $(-1.87)$ & \\
\hline
\end{tabular}

See notes in Panel A 
Table 4 (continuation)

PANEL D: $\tau=24$ months

$\Delta I P I_{t, t+\tau}=\alpha+\beta_{1} \sigma_{t}(M)+\beta_{2} X_{t}+\varepsilon_{t+\tau}, \tau=24$

Idiosyncratic Risk. Sample period: 1965:01-2010:07

\begin{tabular}{lcccc}
\hline & $\alpha$ & $\beta_{1}$ & $\beta_{2}$ & Adj.R $^{2}$ \\
\hline \multirow{3}{*}{ Daily Data } & 0.055 & & -2.009 & 1.82 \\
& $(6.94)$ & & $(-2.63)$ & \\
& 0.167 & -0.227 & -1.571 & 22.21 \\
Monthly Data & $(7.43)$ & $(-4.79)$ & $(-1.89)$ & 0.42 \\
& 0.052 & & -1.617 & \\
& $(6.67)$ & & $(-1.34)$ & 22.02 \\
\hline
\end{tabular}

Volatility of SMB Factor. Sample period: 1965:01-2010:07

\begin{tabular}{|c|c|c|c|c|}
\hline & $\alpha$ & $\beta_{1}$ & $\beta_{2}$ & Adj. $R^{2}$ \\
\hline \multirow{4}{*}{ Daily Data } & 0.076 & & -1.385 & 4.19 \\
\hline & $(5.88)$ & & $(-3.05)$ & \\
\hline & 0.174 & -0.219 & -0.808 & 22.42 \\
\hline & $(7.79)$ & $(-4.46)$ & $(-2.26)$ & \\
\hline \multirow{4}{*}{ Monthly Data } & 0.077 & & -0.901 & 1.30 \\
\hline & $(3.80)$ & & $(-1.61)$ & \\
\hline & 0.226 & -0.255 & -1.638 & 25.65 \\
\hline & $(7.87)$ & $(-5.23)$ & $(-3.74)$ & \\
\hline \multicolumn{5}{|c|}{ Volatility of Market Return. Sample period: 1965:01-2010:07 } \\
\hline & $\alpha$ & $\beta_{1}$ & $\beta_{2}$ & Adj. $R^{2}$ \\
\hline \multirow{4}{*}{ Fornari-Mele } & 0.040 & & 0.255 & 0.07 \\
\hline & $(1.56)$ & & $(0.48)$ & \\
\hline & 0.174 & -0.237 & -0.145 & 20.59 \\
\hline & $(5.95)$ & $(-4.88)$ & $(-0.34)$ & \\
\hline \multirow{4}{*}{ Monthly Data } & 0.047 & & -0.014 & 0.00 \\
\hline & $(1.14)$ & & $(-0.02)$ & \\
\hline & 0.261 & -0.257 & -2.002 & 24.22 \\
\hline & $(5.63)$ & $(-5.10)$ & $(-2.71)$ & \\
\hline \multicolumn{5}{|c|}{ VIX. Sample period: 1986:01-2010:07 } \\
\hline & $\alpha$ & $\beta_{1}$ & $\beta_{2}$ & $\operatorname{Adj} . R^{2}$ \\
\hline \multirow{4}{*}{ Last day of each month } & 0.069 & & -0.150 & 2.60 \\
\hline & $(3.30)$ & & $(-1.91)$ & \\
\hline & 0.221 & -0.237 & -0.231 & 24.98 \\
\hline & $(4.83)$ & $(-3.23)$ & $(-2.55)$ & \\
\hline \multicolumn{5}{|c|}{ Dispersion in SPF. Quarterly Data. Sample period: 1968:IV-2010:4 } \\
\hline & $\alpha$ & $\beta_{1}$ & $\beta_{2}$ & $\operatorname{Adj} . R^{2}$ \\
\hline \multirow{4}{*}{$D 2$ for $G D P$ growth } & 0.032 & & 0.005 & -0.33 \\
\hline & $(1.31)$ & & $(0.39)$ & \\
\hline & 0.187 & -0.242 & -0.013 & 22.25 \\
\hline & $(4.69)$ & $(-3.70)$ & $(-1.12)$ & \\
\hline \multirow{4}{*}{$D 3$ for $G D P$ levels } & 0.043 & & -0.003 & -0.62 \\
\hline & $(1.68)$ & & $(-0.05)$ & \\
\hline & 0.202 & -0.251 & -0.078 & 24.08 \\
\hline & (5.34) & $(-3.93)$ & $(-1.61)$ & \\
\hline
\end{tabular}

See notes in Panel A 
Table 5

The Hansen-Jagannathan volatility bound with different portfolio sets

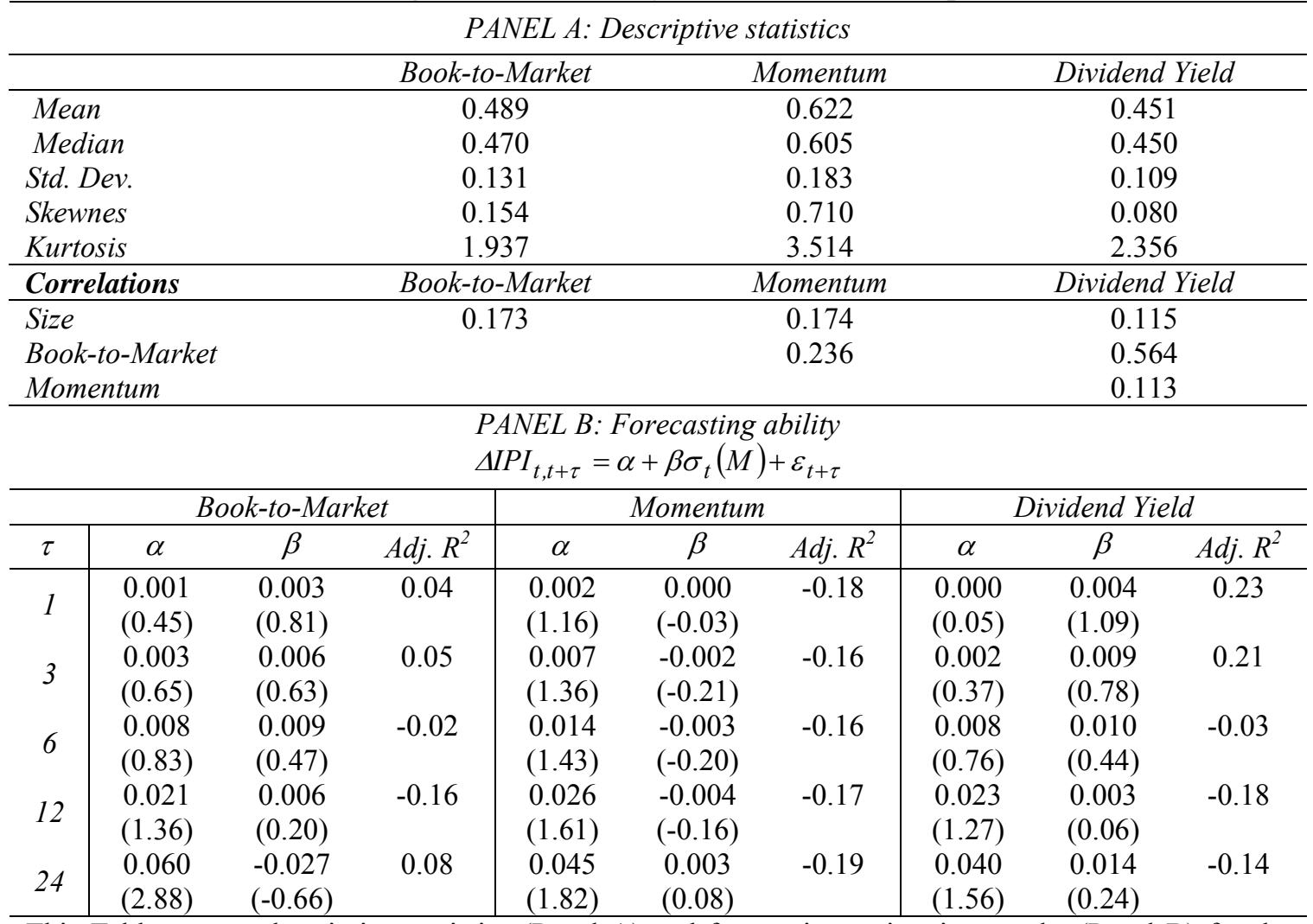

This Table reports descriptive statistics (Panel A) and forecasting estimation results (Panel B) for the Hansen-Jagannathan volatility bound estimated with overlapping sub-periods of five years of monthly returns from book-to-market-, momentum-, and dividend yield-sorted portfolios. The sample period for the estimation of the volatility bound goes from January 1927 to December 2010. The sample period for the forecasting analysis goes from January 1965 to July 2010. Numbers in parentheses are $t$-values based on OLS autocorrelation-robust standard errors. 
Table 6

Markov Switching Models for excess returns on the size-book-to-market-momentum-dividendyield-sorted portfolios

\begin{tabular}{|c|c|c|c|c|c|c|c|c|c|c|}
\hline \multicolumn{11}{|c|}{ PANEL A: Size-sorted portfolios } \\
\hline $\begin{array}{l}\text { Mean } \\
\text { Parameters }\end{array}$ & Size1 & Size2 & Size3 & Size4 & Size5 & Size6 & Size7 & Size8 & Size9 & Size10 \\
\hline$\beta_{0,1}$ & $\begin{array}{l}-0.070 \\
(-4.49)\end{array}$ & $\begin{array}{l}-0.024 \\
(-1.16)\end{array}$ & $\begin{array}{l}-0.013 \\
(-0.61)\end{array}$ & $\begin{array}{l}-0.026 \\
(-1.19)\end{array}$ & $\begin{array}{l}-0.024 \\
(-0.98)\end{array}$ & $\begin{array}{l}-0.023 \\
(-0.97)\end{array}$ & $\begin{array}{l}-0.014 \\
(-0.62)\end{array}$ & $\begin{array}{l}-0.020 \\
(-1.18)\end{array}$ & $\begin{array}{l}-0.013 \\
(-0.65)\end{array}$ & $\begin{array}{l}-0.002 \\
(-0.29)\end{array}$ \\
\hline$\beta_{0,2}$ & $\begin{array}{l}0.041 \\
(5.75)\end{array}$ & $\begin{array}{l}0.004 \\
(0.42)\end{array}$ & $\begin{array}{l}0.007 \\
(0.82)\end{array}$ & $\begin{array}{l}0.015 \\
(1.84)\end{array}$ & $\begin{array}{l}0.008 \\
(1.07)\end{array}$ & $\begin{array}{l}0.000 \\
(0.04)\end{array}$ & $\begin{array}{l}0.007 \\
(1.03)\end{array}$ & $\begin{array}{l}-0.006 \\
(-0.76)\end{array}$ & $\begin{array}{l}-0.002 \\
(-0.30)\end{array}$ & $\begin{array}{l}-0.013 \\
(-1.92)\end{array}$ \\
\hline$\beta_{1,1}$ & $\begin{array}{c}49.979 \\
(5.59)\end{array}$ & $\begin{array}{l}6.894 \\
(0.53)\end{array}$ & $\begin{array}{l}-2.328 \\
(-0.18)\end{array}$ & $\begin{array}{l}2.848 \\
(0.22)\end{array}$ & $\begin{array}{l}0.441 \\
(0.03)\end{array}$ & $\begin{array}{l}0.182 \\
(0.01)\end{array}$ & $\begin{array}{l}-4.402 \\
(-0.32)\end{array}$ & $\begin{array}{l}7.024 \\
(0.76)\end{array}$ & $\begin{array}{l}-3.402 \\
(-0.30)\end{array}$ & $\begin{array}{l}2.283 \\
(0.43)\end{array}$ \\
\hline$\beta_{1,2}$ & $\begin{array}{c}-24.296 \\
(-4.60)\end{array}$ & $\begin{array}{l}6.921 \\
(1.20)\end{array}$ & $\begin{array}{l}5.815 \\
(1.08)\end{array}$ & $\begin{array}{l}0.581 \\
(0.11)\end{array}$ & $\begin{array}{l}5.603 \\
(1.11)\end{array}$ & $\begin{array}{l}9.439 \\
(1.93)\end{array}$ & $\begin{array}{l}4.357 \\
(0.92)\end{array}$ & $\begin{array}{l}12.637 \\
(2.41)\end{array}$ & $\begin{array}{l}9.559 \\
(2.08)\end{array}$ & $\begin{array}{l}14.003 \\
(3.10)\end{array}$ \\
\hline \multicolumn{11}{|c|}{ Variance Parameters } \\
\hline$\lambda_{0,1}$ & $\begin{array}{c}-4.481 \\
(-16.14)\end{array}$ & $\begin{array}{c}-4.998 \\
(-12.87)\end{array}$ & $\begin{array}{c}-5.157 \\
(-13.61)\end{array}$ & $\begin{array}{c}-5.253 \\
(-13.97)\end{array}$ & $\begin{array}{c}-5.491 \\
(-14.79)\end{array}$ & $\begin{array}{c}-5.469 \\
(-13.47)\end{array}$ & $\begin{array}{c}-5.720 \\
(-14.95)\end{array}$ & $\begin{array}{c}-5.783 \\
(-15.92)\end{array}$ & $\begin{array}{c}-5.959 \\
(-14.09)\end{array}$ & $\begin{array}{c}-6.627 \\
(-24.32)\end{array}$ \\
\hline$\lambda_{0,2}$ & $\begin{array}{c}-7.492 \\
(-26.69)\end{array}$ & $\begin{array}{c}-6.827 \\
(-20.95)\end{array}$ & $\begin{array}{c}-6.870 \\
(-20.73)\end{array}$ & $\begin{array}{c}-6.923 \\
(-19.06)\end{array}$ & $\begin{array}{c}-6.924 \\
(-21.36)\end{array}$ & $\begin{array}{c}-6.802 \\
(-21.97)\end{array}$ & $\begin{array}{c}-7.142 \\
(-23.18)\end{array}$ & $\begin{array}{c}-6.933 \\
(-19.05)\end{array}$ & $\begin{array}{c}-7.192 \\
(-24.80)\end{array}$ & $\begin{array}{c}-7.703 \\
(-15.87)\end{array}$ \\
\hline$\lambda_{1,1}$ & $\begin{array}{c}-365.81 \\
(-2.26)\end{array}$ & $\begin{array}{c}141.071 \\
(0.64)\end{array}$ & $\begin{array}{c}160.167 \\
(0.74)\end{array}$ & $\begin{array}{c}159.500 \\
(0.72)\end{array}$ & $\begin{array}{c}244.234 \\
(1.13)\end{array}$ & $\begin{array}{c}147.985 \\
(0.65)\end{array}$ & $\begin{array}{c}318.689 \\
(1.45)\end{array}$ & $\begin{array}{c}235.962 \\
(1.24)\end{array}$ & $\begin{array}{c}258.989 \\
(1.14)\end{array}$ & $\begin{array}{c}388.931 \\
(2.36)\end{array}$ \\
\hline$\lambda_{1,2}$ & $\begin{array}{c}676.603 \\
(4.41)\end{array}$ & $\begin{array}{c}474.787 \\
(2.42)\end{array}$ & $\begin{array}{c}443.129 \\
(2.31)\end{array}$ & $\begin{array}{c}463.020 \\
(2.23)\end{array}$ & $\begin{array}{c}415.489 \\
(2.29)\end{array}$ & $\begin{array}{c}299.247 \\
(1.69)\end{array}$ & $\begin{array}{c}469.299 \\
(2.60)\end{array}$ & $\begin{array}{c}257.520 \\
(1.08)\end{array}$ & $\begin{array}{c}391.428 \\
(2.21)\end{array}$ & $\begin{array}{c}194.780 \\
(0.60)\end{array}$ \\
\hline \multicolumn{11}{|c|}{ Log Likelihood Values } \\
\hline Unrestricted & 766.795 & 755.653 & 776.949 & 796.460 & 821.807 & 853.828 & 867.082 & 879.991 & 927.237 & 979.075 \\
\hline$\beta_{0,1}=\beta_{0,2}$ & 758.036 & 754.411 & 772.024 & 793.675 & 813.282 & 846.706 & 860.999 & 875.468 & 923.544 & 976.734 \\
\hline$\beta_{1,1}=\beta_{1,2}$ & 0.00 & 0.14 & 0.00 & 0.03 & 0.00 & 0.00 & 0.00 & 0.01 & 0.01 & 0.05 \\
\hline$\lambda_{0,1}=\lambda_{0,2}$ & 734.202 & 742.324 & 769.073 & 791.304 & 796.953 & 830.308 & 859.992 & 858.294 & 922.054 & 955.093 \\
\hline$\lambda_{1,1}=\lambda_{1,2}$ & 0.00 & 0.00 & 0.00 & 0.00 & 0.00 & 0.00 & 0.00 & 0.00 & 0.00 & 0.00 \\
\hline
\end{tabular}

The following Markov switching model is estimated for each portfolio $i$, within the set of portfolios indicated at the top of each panel,

$$
\begin{aligned}
& R_{t+1}^{i}-R_{f t+1}=\beta_{0, S}^{i}+\beta_{1, S}^{i} D e f_{t}+\varepsilon_{t+1}^{i} \\
& \varepsilon_{t+1}^{i} \sim N\left(0, h_{S t+1}^{i}\right), \log \left(h_{S t+1}^{i}\right)=\lambda_{0, S}^{i}+\lambda_{1, S}^{i} D e f_{t}
\end{aligned}
$$

where $R$ is the monthly return on the portfolio, $R_{f}$ is the risk free rate, and Def is an aggregate default premium calculated as the spread between Baa corporate bond rates and 10-year government bond rates. In the two first blocks, we report parameter estimates and $t$-values (in parentheses). The last rows provide the log Likelihood value for the specification above and also for two restricted cases in order to test the null of symmetry across states in the mean equation, on the one hand, and in the variance equation, on the other. Numbers bellow the log Likelihood values are $p$-values associated to Likelihood ratio tests. Sample period goes from January 1965 to December 2010. 
Table 6 (continuation)

\begin{tabular}{|c|c|c|c|c|c|c|c|c|c|c|}
\hline \multicolumn{11}{|c|}{ PANEL B: Book-to-market-sorted portfolios } \\
\hline $\begin{array}{l}\text { Mean } \\
\text { Parameters }\end{array}$ & BM1 & BM2 & BM3 & BM4 & BM5 & BM6 & BM7 & BM8 & BM9 & BM10 \\
\hline$\beta_{0,1}$ & $\begin{array}{l}-0.003 \\
(-0.35)\end{array}$ & $\begin{array}{l}-0.026 \\
(-2.63)\end{array}$ & $\begin{array}{l}-0.007 \\
(-0.77)\end{array}$ & $\begin{array}{l}-0.002 \\
(-0.07)\end{array}$ & $\begin{array}{l}0.002 \\
(0.10)\end{array}$ & $\begin{array}{l}-0.016 \\
(-0.62)\end{array}$ & $\begin{array}{l}-0.022 \\
(-1.70)\end{array}$ & $\begin{array}{c}0.000 \\
(-0.02)\end{array}$ & $\begin{array}{l}-0.003 \\
(-0.25)\end{array}$ & $\begin{array}{l}-0.003 \\
(-0.25)\end{array}$ \\
\hline$\beta_{0,2}$ & $\begin{array}{l}0.008 \\
(1.18)\end{array}$ & $\begin{array}{l}0.005 \\
(0.96)\end{array}$ & $\begin{array}{l}0.012 \\
(1.61)\end{array}$ & $\begin{array}{l}-0.005 \\
(-0.74)\end{array}$ & $\begin{array}{l}-0.005 \\
(-0.81)\end{array}$ & $\begin{array}{l}0.003 \\
(0.47)\end{array}$ & $\begin{array}{l}0.020 \\
(2.80)\end{array}$ & $\begin{array}{l}0.007 \\
(1.30)\end{array}$ & $\begin{array}{l}-0.001 \\
(-0.08)\end{array}$ & $\begin{array}{l}0.008 \\
(1.02)\end{array}$ \\
\hline$\beta_{1,1}$ & $\begin{array}{l}2.676 \\
(0.50)\end{array}$ & $\begin{array}{l}21.240 \\
(3.49)\end{array}$ & $\begin{array}{l}6.769 \\
(1.31)\end{array}$ & $\begin{array}{c}-18.721 \\
(-1.31)\end{array}$ & $\begin{array}{c}-11.168 \\
(-1.04)\end{array}$ & $\begin{array}{l}-4.413 \\
(-0.32)\end{array}$ & $\begin{array}{l}11.829 \\
(1.56)\end{array}$ & $\begin{array}{l}-6.986 \\
(-0.64)\end{array}$ & $\begin{array}{l}3.099 \\
(0.52)\end{array}$ & $\begin{array}{l}3.709 \\
(0.54)\end{array}$ \\
\hline$\beta_{1,2}$ & $\begin{array}{l}-0.832 \\
(-0.16)\end{array}$ & $\begin{array}{l}-1.735 \\
(-0.40)\end{array}$ & $\begin{array}{l}-4.265 \\
(-0.74)\end{array}$ & $\begin{array}{l}10.087 \\
(2.37)\end{array}$ & $\begin{array}{l}10.375 \\
(2.44)\end{array}$ & $\begin{array}{l}5.010 \\
(1.25)\end{array}$ & $\begin{array}{l}-4.731 \\
(-0.98)\end{array}$ & $\begin{array}{l}2.402 \\
(0.65)\end{array}$ & $\begin{array}{l}8.962 \\
(1.96)\end{array}$ & $\begin{array}{l}2.999 \\
(0.55)\end{array}$ \\
\hline \multicolumn{11}{|c|}{ Variance Parameters } \\
\hline$\lambda_{0,1}$ & $\begin{array}{c}-6.046 \\
(-25.63)\end{array}$ & $\begin{array}{c}-5.670 \\
(-19.38)\end{array}$ & $\begin{array}{c}-6.011 \\
(-26.86)\end{array}$ & $\begin{array}{c}-5.474 \\
(-10.35)\end{array}$ & $\begin{array}{c}-5.792 \\
(-13.86)\end{array}$ & $\begin{array}{c}-5.851 \\
(-10.29)\end{array}$ & $\begin{array}{c}-6.363 \\
(-20.57)\end{array}$ & $\begin{array}{c}-6.313 \\
(-13.91)\end{array}$ & $\begin{array}{c}-6.198 \\
(-23.31)\end{array}$ & $\begin{array}{c}-6.158 \\
(-32.49)\end{array}$ \\
\hline$\lambda_{0,2}$ & $\begin{array}{c}-7.650 \\
(-14.20)\end{array}$ & $\begin{array}{c}-8.519 \\
(-29.90)\end{array}$ & $\begin{array}{c}-8.253 \\
(-23.65)\end{array}$ & $\begin{array}{c}-7.299 \\
(-30.71)\end{array}$ & $\begin{array}{c}-7.301 \\
(-25.24)\end{array}$ & $\begin{array}{c}-7.344 \\
(-30.78)\end{array}$ & $\begin{array}{c}-7.990 \\
(-19.94)\end{array}$ & $\begin{array}{c}-7.555 \\
(-24.26)\end{array}$ & $\begin{array}{c}-6.407 \\
(-13.35)\end{array}$ & $\begin{array}{c}-7.479 \\
(-20.57)\end{array}$ \\
\hline$\lambda_{1,1}$ & $\begin{array}{c}239.459 \\
(1.68)\end{array}$ & $\begin{array}{c}-191.70 \\
(-1.02)\end{array}$ & $\begin{array}{l}64.165 \\
(0.45)\end{array}$ & $\begin{array}{l}63.275 \\
(0.22)\end{array}$ & $\begin{array}{c}130.531 \\
(0.54)\end{array}$ & $\begin{array}{c}278.189 \\
(0.88)\end{array}$ & $\begin{array}{c}377.339 \\
(2.39)\end{array}$ & $\begin{array}{c}557.231 \\
(2.44)\end{array}$ & $\begin{array}{c}333.301 \\
(2.43)\end{array}$ & $\begin{array}{c}574.048 \\
(5.57)\end{array}$ \\
\hline$\lambda_{1,2}$ & $\begin{array}{c}373.879 \\
(0.92)\end{array}$ & $\begin{array}{c}1073.89 \\
(6.78)\end{array}$ & $\begin{array}{c}737.350 \\
(3.23)\end{array}$ & $\begin{array}{c}517.349 \\
(3.72)\end{array}$ & $\begin{array}{c}401.007 \\
(2.24)\end{array}$ & $\begin{array}{c}492.156 \\
(3.41)\end{array}$ & $\begin{array}{c}658.316 \\
(2.63)\end{array}$ & $\begin{array}{c}490.760 \\
(2.56)\end{array}$ & $\begin{array}{c}-472.33 \\
(-1.55)\end{array}$ & $\begin{array}{c}521.853 \\
(2.19)\end{array}$ \\
\hline \multicolumn{11}{|c|}{ Log Likelihood Values } \\
\hline Unrestricted & 867.423 & 913.921 & 917.672 & 918.529 & 949.512 & 947.735 & 955.242 & 959.573 & 922.640 & 842.693 \\
\hline$\beta_{0,1}=\beta_{0,2}$ & 867.494 & 908.843 & 916.719 & 912.444 & 946.100 & 942.729 & 949.933 & 957.915 & 920.195 & 802.594 \\
\hline$\beta_{1,1}=\beta_{1,2}$ & 0.47 & 0.00 & 0.19 & 0.00 & 0.02 & 0.00 & 0.00 & 0.10 & 0.04 & 0.00 \\
\hline$\lambda_{0,1}=\lambda_{0,2}$ & 857.118 & 903.996 & 899.221 & 912.029 & 929.102 & 941.709 & 945.883 & 945.602 & 907.837 & 803.439 \\
\hline$\lambda_{1,1}=\lambda_{1,2}$ & 0.00 & 0.00 & 0.00 & 0.00 & 0.00 & 0.00 & 0.00 & 0.00 & 0.00 & 0.00 \\
\hline
\end{tabular}


Table 6 (continuation)

\begin{tabular}{|c|c|c|c|c|c|c|c|c|c|c|}
\hline \multicolumn{11}{|c|}{ PANEL C: Momentum-sorted portfolios } \\
\hline $\begin{array}{l}\text { Mean } \\
\text { Parameters }\end{array}$ & Mom1 & Mom2 & Mom3 & Mom4 & Mom5 & Mom6 & Mom7 & Mom8 & Mom9 & Mom10 \\
\hline$\beta_{0,1}$ & $\begin{array}{l}0.011 \\
(0.46)\end{array}$ & $\begin{array}{l}-0.037 \\
(-2.13)\end{array}$ & $\begin{array}{l}-0.009 \\
(-0.68)\end{array}$ & $\begin{array}{l}-0.027 \\
(-1.58)\end{array}$ & $\begin{array}{l}-0.018 \\
(-1.12)\end{array}$ & $\begin{array}{l}-0.016 \\
(-1.47)\end{array}$ & $\begin{array}{l}-0.024 \\
(-0.82)\end{array}$ & $\begin{array}{l}-0.010 \\
(-0.49)\end{array}$ & $\begin{array}{l}0.006 \\
(0.23)\end{array}$ & $\begin{array}{l}-0.005 \\
(-0.19)\end{array}$ \\
\hline$\beta_{0,2}$ & $\begin{array}{l}-0.020 \\
(-2.33)\end{array}$ & $\begin{array}{l}-0.011 \\
(-1.48)\end{array}$ & $\begin{array}{l}-0.013 \\
(-2.31)\end{array}$ & $\begin{array}{l}-0.012 \\
(-2.05)\end{array}$ & $\begin{array}{l}-0.002 \\
(-0.41)\end{array}$ & $\begin{array}{l}0.000 \\
(0.02)\end{array}$ & $\begin{array}{l}-0.002 \\
(-0.30)\end{array}$ & $\begin{array}{l}0.003 \\
(0.48)\end{array}$ & $\begin{array}{l}0.002 \\
(0.31)\end{array}$ & $\begin{array}{l}0.009 \\
(1.01)\end{array}$ \\
\hline$\beta_{1,1}$ & $\begin{array}{c}-19.814 \\
(-1.21)\end{array}$ & $\begin{array}{l}16.969 \\
(1.67)\end{array}$ & $\begin{array}{l}4.266 \\
(0.50)\end{array}$ & $\begin{array}{l}9.028 \\
(0.93)\end{array}$ & $\begin{array}{l}1.985 \\
(0.20)\end{array}$ & $\begin{array}{l}8.542 \\
(1.35)\end{array}$ & $\begin{array}{l}3.199 \\
(0.21)\end{array}$ & $\begin{array}{l}1.879 \\
(0.19)\end{array}$ & $\begin{array}{c}-10.238 \\
(-0.80)\end{array}$ & $\begin{array}{l}-0.582 \\
(-0.04)\end{array}$ \\
\hline$\beta_{1,2}$ & $\begin{array}{l}14.843 \\
(2.44)\end{array}$ & $\begin{array}{l}12.209 \\
(2.40)\end{array}$ & $\begin{array}{l}12.748 \\
(3.10)\end{array}$ & $\begin{array}{l}13.528 \\
(3.32)\end{array}$ & $\begin{array}{l}7.193 \\
(1.85)\end{array}$ & $\begin{array}{l}5.601 \\
(1.31)\end{array}$ & $\begin{array}{l}6.795 \\
(1.69)\end{array}$ & $\begin{array}{l}4.773 \\
(1.14)\end{array}$ & $\begin{array}{l}6.316 \\
(1.69)\end{array}$ & $\begin{array}{l}6.473 \\
(1.31)\end{array}$ \\
\hline \multicolumn{11}{|c|}{ Variance Parameters } \\
\hline$\lambda_{0,1}$ & $\begin{array}{c}-5.634 \\
(-17.42)\end{array}$ & $\begin{array}{c}-5.683 \\
(-17.07)\end{array}$ & $\begin{array}{c}-5.990 \\
(-23.16)\end{array}$ & $\begin{array}{c}-5.833 \\
(-16.34)\end{array}$ & $\begin{array}{c}-5.810 \\
(-13.49)\end{array}$ & $\begin{array}{c}-6.002 \\
(-20.89)\end{array}$ & $\begin{array}{l}-5.231 \\
(-6.85)\end{array}$ & $\begin{array}{c}-5.467 \\
(-10.99)\end{array}$ & $\begin{array}{l}-4.883 \\
(-9.94)\end{array}$ & $\begin{array}{c}-4.969 \\
(-13.82)\end{array}$ \\
\hline$\lambda_{0,2}$ & $\begin{array}{c}-7.295 \\
(-18.52)\end{array}$ & $\begin{array}{c}-7.118 \\
(-22.68)\end{array}$ & $\begin{array}{c}-8.297 \\
(-26.30)\end{array}$ & $\begin{array}{c}-7.324 \\
(-25.66)\end{array}$ & $\begin{array}{c}-7.724 \\
(-31.69)\end{array}$ & $\begin{array}{c}-7.274 \\
(-17.24)\end{array}$ & $\begin{array}{c}-6.945 \\
(-28.10)\end{array}$ & $\begin{array}{c}-6.817 \\
(-22.49)\end{array}$ & $\begin{array}{c}-6.143 \\
(-21.81)\end{array}$ & $\begin{array}{c}-5.772 \\
(-16.08)\end{array}$ \\
\hline$\lambda_{1,1}$ & $\begin{array}{c}703.209 \\
(4.02)\end{array}$ & $\begin{array}{c}468.410 \\
(2.81)\end{array}$ & $\begin{array}{c}420.961 \\
(2.97)\end{array}$ & $\begin{array}{c}307.059 \\
(1.58)\end{array}$ & $\begin{array}{c}190.483 \\
(0.69)\end{array}$ & $\begin{array}{c}241.803 \\
(1.41)\end{array}$ & $\begin{array}{l}-5.242 \\
(-0.01)\end{array}$ & $\begin{array}{c}49.476 \\
(0.16)\end{array}$ & $\begin{array}{c}-146.50 \\
(-0.54)\end{array}$ & $\begin{array}{l}72.041 \\
(0.32)\end{array}$ \\
\hline$\lambda_{1,2}$ & $\begin{array}{c}730.955 \\
(2.86)\end{array}$ & $\begin{array}{c}398.052 \\
(1.79)\end{array}$ & $\begin{array}{c}942.209 \\
(4.33)\end{array}$ & $\begin{array}{c}468.387 \\
(2.49)\end{array}$ & $\begin{array}{c}592.318 \\
(4.07)\end{array}$ & $\begin{array}{c}168.168 \\
(0.61)\end{array}$ & $\begin{array}{c}189.129 \\
(1.36)\end{array}$ & $\begin{array}{c}106.189 \\
(0.61)\end{array}$ & $\begin{array}{c}-254.58 \\
(-1.52)\end{array}$ & $\begin{array}{c}-282.09 \\
(-1.31)\end{array}$ \\
\hline \multicolumn{11}{|c|}{ Log Likelihood Values } \\
\hline Unrestricted & 699.502 & 818.125 & 892.998 & 926.152 & 963.736 & 946.305 & 952.437 & 935.104 & 895.850 & 758.868 \\
\hline$\beta_{0,1}=\beta_{0,2}$ & 699.113 & 814.733 & 891.787 & 923.532 & 959.920 & 944.992 & 949.371 & 924.767 & 892.276 & 755.860 \\
\hline$\beta_{1,1}=\beta_{1,2}$ & 0.34 & 0.02 & 0.15 & 0.04 & 0.01 & 0.13 & 0.02 & 0.00 & 0.01 & 0.02 \\
\hline$\lambda_{0,1}=\lambda_{0,2}$ & 663.410 & 774.061 & 861.906 & 911.582 & 932.061 & 929.441 & 929.301 & 928.468 & 886.252 & 733.869 \\
\hline$\lambda_{1,1}=\lambda_{1,2}$ & 0.00 & 0.00 & 0.00 & 0.00 & 0.00 & 0.00 & 0.00 & 0.00 & 0.00 & 0.00 \\
\hline
\end{tabular}

See notes in Panel A. 
Table 6 (continuation)

\begin{tabular}{|c|c|c|c|c|c|c|c|c|c|c|}
\hline \multicolumn{11}{|c|}{ PANEL D: Dividend yield-sorted portfolios } \\
\hline $\begin{array}{l}\text { Mean } \\
\text { Parameters }\end{array}$ & DY1 & DY2 & DY3 & DY4 & DY5 & DY6 & DY7 & DY8 & DY9 & DY10 \\
\hline$\beta_{0,1}$ & $\begin{array}{l}-0.005 \\
(-0.51)\end{array}$ & $\begin{array}{l}-0.018 \\
(-0.26)\end{array}$ & $\begin{array}{l}0.000 \\
(0.05)\end{array}$ & $\begin{array}{l}-0.002 \\
(-0.21)\end{array}$ & $\begin{array}{l}-0.011 \\
(-1.48)\end{array}$ & $\begin{array}{l}-0.002 \\
(-0.26)\end{array}$ & $\begin{array}{l}-0.010 \\
(-0.46)\end{array}$ & $\begin{array}{l}-0.004 \\
(-0.36)\end{array}$ & $\begin{array}{l}0.007 \\
(0.89)\end{array}$ & $\begin{array}{l}-0.013 \\
(-1.52)\end{array}$ \\
\hline$\beta_{0,2}$ & $\begin{array}{l}0.006 \\
(0.67)\end{array}$ & $\begin{array}{l}0.000 \\
(0.05)\end{array}$ & $\begin{array}{l}-0.003 \\
(-0.36)\end{array}$ & $\begin{array}{l}-0.013 \\
(-1.48)\end{array}$ & $\begin{array}{l}0.021 \\
(2.41)\end{array}$ & $\begin{array}{l}0.004 \\
(0.58)\end{array}$ & $\begin{array}{c}0.000 \\
(-0.08)\end{array}$ & $\begin{array}{l}-0.004 \\
(-0.57)\end{array}$ & $\begin{array}{l}-0.003 \\
(-0.36)\end{array}$ & $\begin{array}{l}0.011 \\
(1.58)\end{array}$ \\
\hline$\beta_{1,1}$ & $\begin{array}{l}3.968 \\
(0.66)\end{array}$ & $\begin{array}{c}-17.189 \\
(-0.48)\end{array}$ & $\begin{array}{l}2.548 \\
(0.49)\end{array}$ & $\begin{array}{l}0.708 \\
(0.11)\end{array}$ & $\begin{array}{l}9.547 \\
(1.83)\end{array}$ & $\begin{array}{l}3.953 \\
(0.96)\end{array}$ & $\begin{array}{l}-4.909 \\
(-0.41)\end{array}$ & $\begin{array}{l}1.737 \\
(0.27)\end{array}$ & $\begin{array}{l}1.972 \\
(0.39)\end{array}$ & $\begin{array}{l}7.974 \\
(1.35)\end{array}$ \\
\hline$\beta_{1,2}$ & $\begin{array}{l}2.897 \\
(0.47)\end{array}$ & $\begin{array}{l}4.790 \\
(1.12)\end{array}$ & $\begin{array}{l}6.666 \\
(1.10)\end{array}$ & $\begin{array}{l}15.839 \\
(2.92)\end{array}$ & $\begin{array}{l}-9.744 \\
(-1.68)\end{array}$ & $\begin{array}{l}2.132 \\
(0.43)\end{array}$ & $\begin{array}{l}6.635 \\
(1.69)\end{array}$ & $\begin{array}{l}9.875 \\
(2.41)\end{array}$ & $\begin{array}{l}1.761 \\
(0.32)\end{array}$ & $\begin{array}{l}-1.127 \\
(-0.25)\end{array}$ \\
\hline \multicolumn{11}{|c|}{ Variance Parameters } \\
\hline$\lambda_{0,1}$ & $\begin{array}{c}-5.704 \\
(-28.44)\end{array}$ & $\begin{array}{l}-4.959 \\
(-3.95)\end{array}$ & $\begin{array}{c}-6.056 \\
(-27.54)\end{array}$ & $\begin{array}{c}-5.738 \\
(-18.21)\end{array}$ & $\begin{array}{c}-6.594 \\
(-39.85)\end{array}$ & $\begin{array}{c}-6.047 \\
(-32.64)\end{array}$ & $\begin{array}{c}-5.780 \\
(-12.26)\end{array}$ & $\begin{array}{c}-6.259 \\
(-20.37)\end{array}$ & $\begin{array}{c}-7.389 \\
(-16.41)\end{array}$ & $\begin{array}{c}-7.275 \\
(-30.00)\end{array}$ \\
\hline$\lambda_{0,2}$ & $\begin{array}{c}-7.439 \\
(-15.00)\end{array}$ & $\begin{array}{c}-6.790 \\
(-28.79)\end{array}$ & $\begin{array}{c}-6.304 \\
(-13.57)\end{array}$ & $\begin{array}{c}-6.899 \\
(-15.23)\end{array}$ & $\begin{array}{c}-8.301 \\
(-14.29)\end{array}$ & $\begin{array}{c}-6.815 \\
(-14.78)\end{array}$ & $\begin{array}{c}-7.163 \\
(-25.87)\end{array}$ & $\begin{array}{c}-7.241 \\
(-18.31)\end{array}$ & $\begin{array}{c}-6.723 \\
(-23.71)\end{array}$ & $\begin{array}{c}-7.728 \\
(-18.87)\end{array}$ \\
\hline$\lambda_{1,1}$ & $\begin{array}{c}179.864 \\
(1.55)\end{array}$ & $\begin{array}{c}87.796 \\
(0.11)\end{array}$ & $\begin{array}{c}198.364 \\
(1.57)\end{array}$ & $\begin{array}{l}39.767 \\
(0.22)\end{array}$ & $\begin{array}{c}456.071 \\
(4.55)\end{array}$ & $\begin{array}{c}26.114 \\
(0.26)\end{array}$ & $\begin{array}{c}239.765 \\
(0.94)\end{array}$ & $\begin{array}{c}297.389 \\
(1.71)\end{array}$ & $\begin{array}{c}144.743 \\
(0.52)\end{array}$ & $\begin{array}{c}840.509 \\
(6.80)\end{array}$ \\
\hline$\lambda_{1,2}$ & $\begin{array}{c}476.672 \\
(1.37)\end{array}$ & $\begin{array}{c}364.089 \\
(2.66)\end{array}$ & $\begin{array}{c}-648.05 \\
(-1.97)\end{array}$ & $\begin{array}{c}-32.232 \\
(-0.12)\end{array}$ & $\begin{array}{c}651.240 \\
(1.77)\end{array}$ & $\begin{array}{c}-350.42 \\
(-1.10)\end{array}$ & $\begin{array}{c}334.197 \\
(1.96)\end{array}$ & $\begin{array}{c}143.346 \\
(0.56)\end{array}$ & $\begin{array}{c}465.150 \\
(2.99)\end{array}$ & $\begin{array}{c}310.811 \\
(1.24)\end{array}$ \\
\hline \multicolumn{11}{|c|}{ Log Likelihood Values } \\
\hline Unrestricted & 813.200 & 873.457 & 889.385 & 911.985 & 919.495 & 951.178 & 949.151 & 976.257 & 996.803 & 1003.64 \\
\hline$\beta_{0,1}=\beta_{0,2}$ & 811.876 & 872.072 & 868.268 & 908.426 & 918.727 & 951.117 & 945.972 & 973.814 & 981.558 & 1000.53 \\
\hline$\beta_{1,1}=\beta_{1,2}$ & 0.13 & 0.13 & 0.00 & 0.01 & 0.23 & 0.47 & 0.02 & 0.04 & 0.00 & 0.02 \\
\hline$\lambda_{0,1}=\lambda_{0,2}$ & 807.528 & 869.476 & 868.960 & 902.391 & 906.684 & 933.945 & 943.797 & 952.326 & 982.303 & 985.014 \\
\hline$\lambda_{1,1}=\lambda_{1,2}$ & 0.00 & 0.01 & 0.00 & 0.00 & 0.00 & 0.00 & 0.00 & 0.00 & 0.00 & 0.00 \\
\hline
\end{tabular}

See notes in Panel A. 
Figure 1

The HJ bound estimated with the overlapping 60-month periods of returns of 10 size-sorted portfolios from January 1927 to December 2010

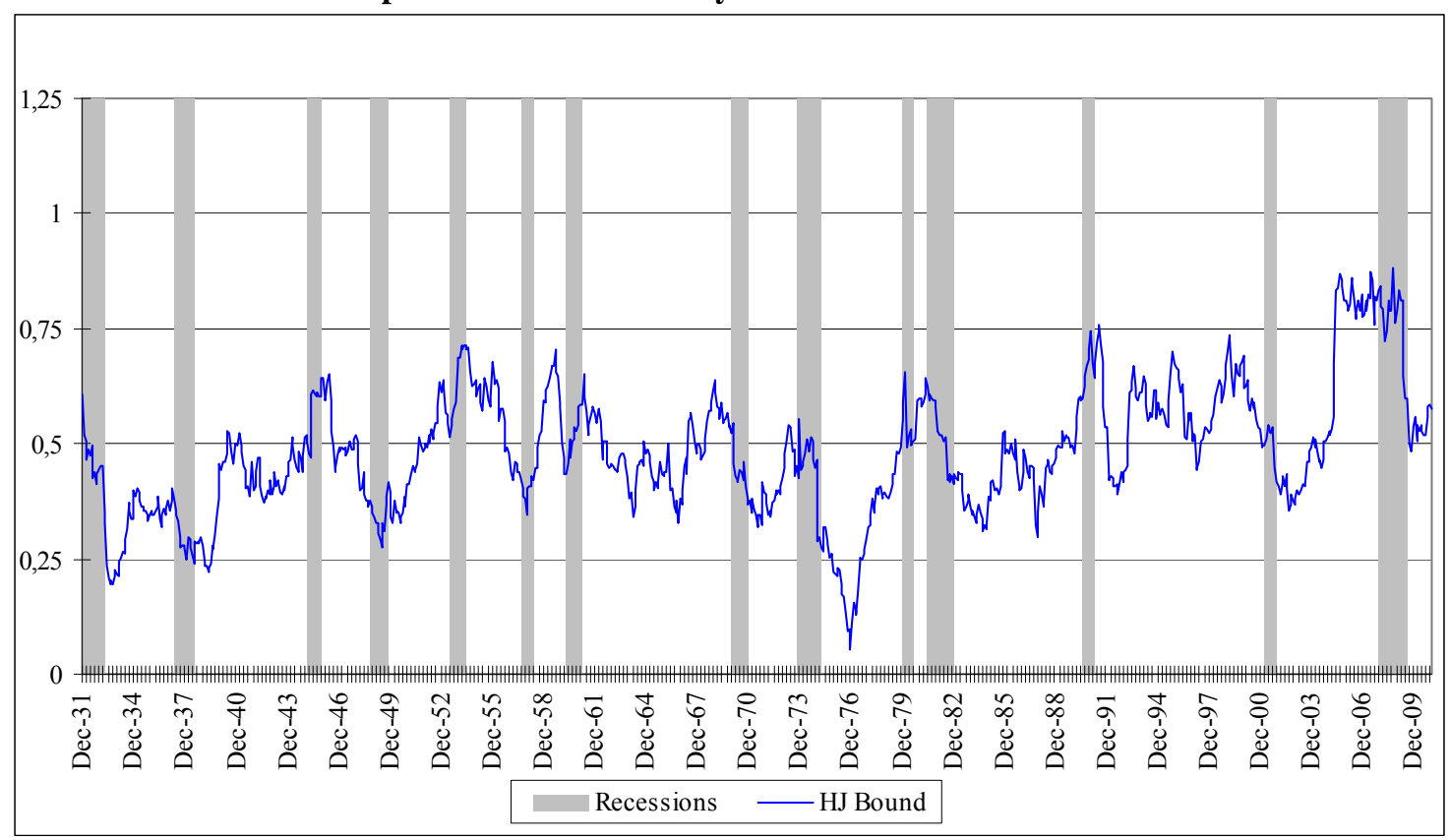

